\title{
Current Status and Future Prospects of Warm Spray Technology
}

\author{
Seiji Kuroda, Makoto Watanabe, KeeHyun Kim, and Hiroshi Katanoda
}

(Submitted January 4, 2011; in revised form March 4, 2011)

\begin{abstract}
A modification of high-velocity oxy-fuel (HVOF) thermal spray process named as warm spray (WS) has been developed. By injecting room temperature inert gas into the combustion gas jet of $\mathrm{HVOF}$, the temperature of the propellant gas can be controlled in a range approximately from 2300 to $1000 \mathrm{~K}$ so that many powder materials can be deposited in thermally softened state at high impact velocity. In this review, the characteristics of WS process were analyzed by using gas dynamic simulation of the flow field and heating/acceleration of powder particles in comparison with HVOF, cold spray (CS), and high-velocity air-fuel (HVAF) spray. Transmission electron microscopy of WS and CS titanium splats revealed marked differences in the microstructures stemming from the different impact temperatures. Mechanical properties of several metallic coatings formed under different WS and CS conditions were compared. Characteristics of WC-Co coatings made by WS were demonstrated for wear resistant applications.
\end{abstract}

Keywords cermet coatings, cold gas dynamic spraying, gas dynamics simulation, HVOF process, titanium, oxidation during spraying, TEM, wear and corrosion

\section{Introduction}

Since the first papers on warm spraying (WS) were published in 2006 (Ref 1,2), significant efforts have been made to understand its process fundamentals (Ref 3-14) as well as to explore potential advantages of coatings made by the process for industrial applications (Ref 15-20). Various thermal spray processes are classified schematically in terms of particles' temperature and velocity on a so-called process map (Ref 21-23) as shown in Fig. 1. In classical processes such as wire arc and flame spray, powder particles are almost completely melted and the impacting velocity onto the substrate is usually below $200 \mathrm{~m} / \mathrm{s}$. Plasma spray expanded the capability of thermal spray to a significantly high temperature range to include refractory materials such as oxides and high melting points metals into the sprayable feedstock materials. The particles' velocity increased remarkably by the advent of highvelocity oxy-fuel (HVOF) process in the 1980s and the process includes a certain proportion of unmolten particles, of which amount depends on both the feedstock material and the process conditions. In 1990s, cold spray (CS) was invented, by which completely solid particles are

Seiji Kuroda, Makoto Watanabe, and KeeHyun Kim, National Institute for Material Science, Sengen 1-2-1, Tsukuba, Ibaraki 305-0047, Japan; and Hiroshi Katanoda, Kagoshima University, Korimoto 1-21-24, Kagoshima 890-0065, Japan. Contact e-mail: kuroda.seiji@nims.go.jp. projected onto the substrate to form coatings (Ref 24-26). The minimum velocity required to induce bonding of particles by adiabatic shear instability is defined as critical velocity, which depends on each metal's physical properties (Ref 27). The warm spray process is based on highvelocity impact bonding of powder particles, which is similar to cold spraying, but the temperature of the particles at impact is significantly higher and often very close to the melting point of the material. Therefore, warm spray may be regarded as a process to fill the gap between $\mathrm{HVOF}$ and $\mathrm{CS}$.

In this review article, history of warm spray development is introduced first, then the characteristics of the process are discussed by making comparison with CS, HVOF, and high-velocity air-fuel (HVAF) spray. Microstructure and mechanical properties of WS coatings are discussed for titanium and other metals, and application oriented results related to WC-based cermet coatings are introduced. At the end, conclusions with some future perspectives of the WS process are given.

\section{Historical Review of Process Development Based on HVOF}

\subsection{Corrosion Barrier Coatings in Ultra-Steel Project}

A Japanese national project called "Ultra-Steel Project" was conducted at the National Institute for Materials Science (NIMS) from 1997 to 2006. It was aimed to develop a family of new structural steels with remarkably upgraded properties such as strength, corrosion resistance, and creep resistance. The developed steels include high strength (1800 MPa class) low-alloy steels with submicron grains, new weathering steels with $\mathrm{Al}$ and $\mathrm{Si}$ addition, high-nitrogen bearing stainless steels, and heat resistant 
steels with increased creep life by new alloy designs. As an approach to develop corrosion resistant steels for marine environments, dense corrosion resistant metallic coatings, which can be applied to large structures, were investigated. As an example of targeted applications, large pillars of the Tokyo Bay Bridge are shown in Fig. 2(a) after completion with its superstructure, and in Fig. 2(b) is shown a pillar before it is sunk onto the seabed. While the immersed portion of the pillar is protected by a combination of heavy-duty painting (black) and cathodic protection by using aluminum anodes, the splash zone requires barrier-type protection. In this particular construction, titanium-clad steel was developed and sophisticated welding procedure was adopted in order to fabricate a fully connected titanium surface layer in the zone as

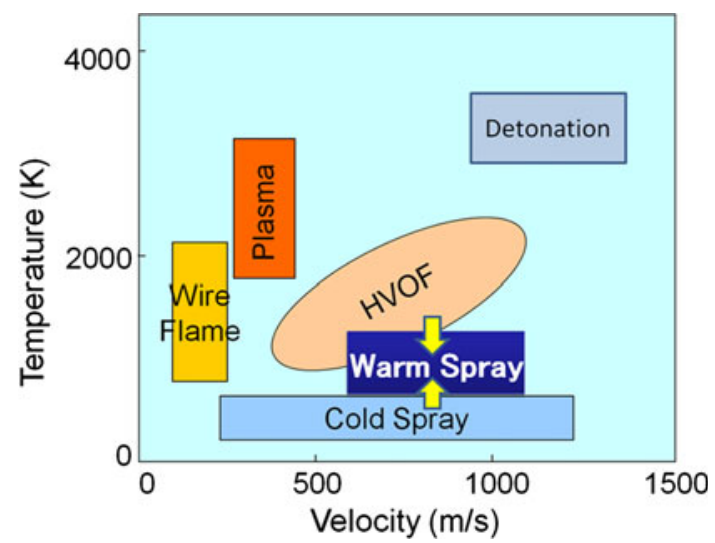

Fig. 1 Schematic classification of various thermal spray processes by the temperature and velocity of sprayed particles
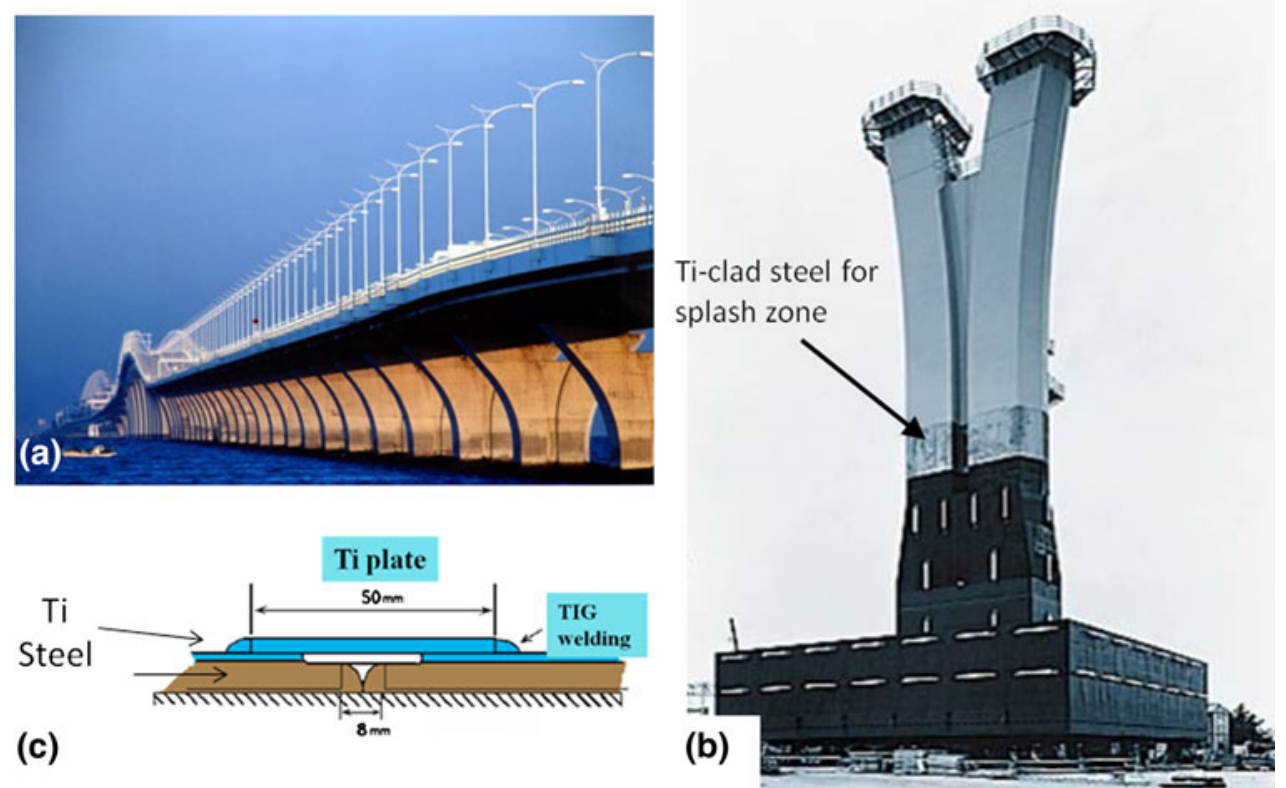

Fig. 2 Ti-clad steel used for pillars of Tokyo Bay Aqua-Line Highway Bridge. (a) Overview, (b) pillar on the ground before installation onto the seabed, and (c) welding scheme adopted to connect the clad steel shown in Fig. 2(c) (Ref 28). If such layer of titanium or alloys such as stainless steels and Ni-base alloys can be produced by thermal spray, it should be more economical and widely applicable. With such an ambitious goal in mind, the process chosen by the authors' group was a HVOF process powered by combustion of kerosene and oxygen as it was known to produce very dense coatings with less degree of oxidation due to its high powder velocity and relatively low gas temperature as compared to other systems powdered by gaseous fuels. A schematic drawing of one commercially available apparatus (JP5000, Praxair TAFA, USA) is shown in Fig. 3(a). Kerosene and oxygen are injected into the combustion chamber, where the mixture is continuously combusted to generate a high temperature gas at a relatively high pressure close to $1 \mathrm{MPa}$. The hot gas is allowed to emanate through a converging-diverging nozzle and becomes a supersonic jet by expansion (Ref 29). Feedstock powder is injected through a couple of powder feed ports and the powder particles are accelerated and heated in the straight barrel section. Substrate is usually placed at $200-400 \mathrm{~mm}$ downstream from the barrel exit, where the accelerated particles impinge onto the substrate at a velocity usually over $400 \mathrm{~m} / \mathrm{s}$. The temperature and velocity of powder particles are highly sensitive to the powder size and density as well as the HVOF operating conditions as described in many literatures (Ref 30-33). Little information, however, was available about the corrosion performance of metal coatings by this process at the time ( $\operatorname{Ref} 34)$.

\subsection{Corrosion Performance of HVOF Coatings}

At an early stage of the project, it became clear that titanium is too reactive for the process as the material reacts with the combustion gas and the surrounding air

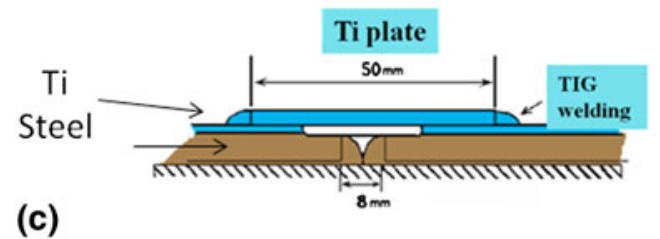

(c)

(b) . 


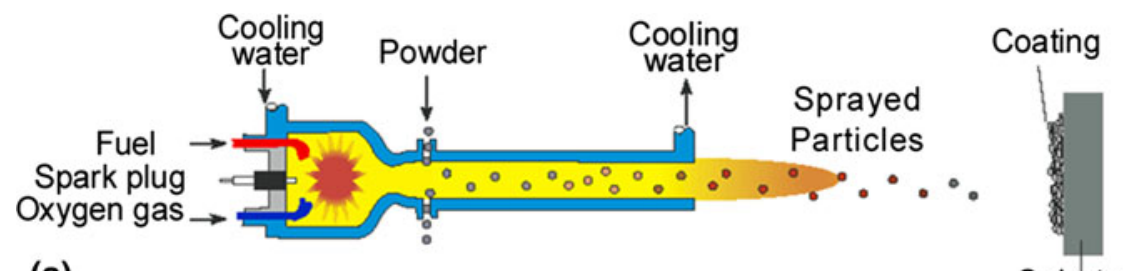

(a)

Substrate

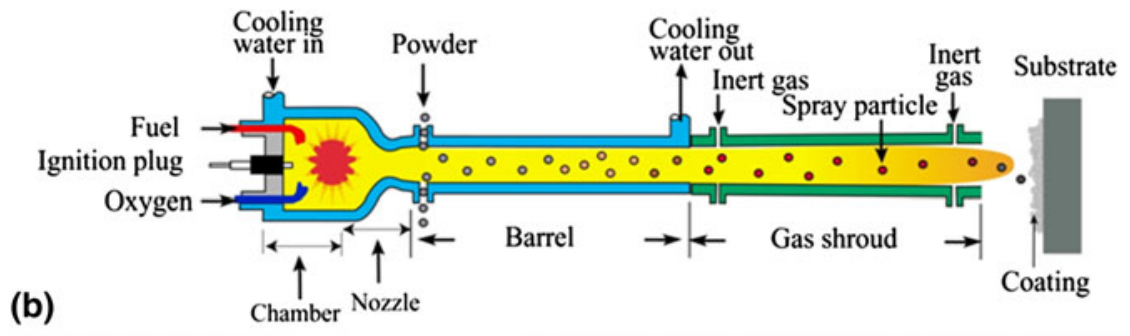

(b)
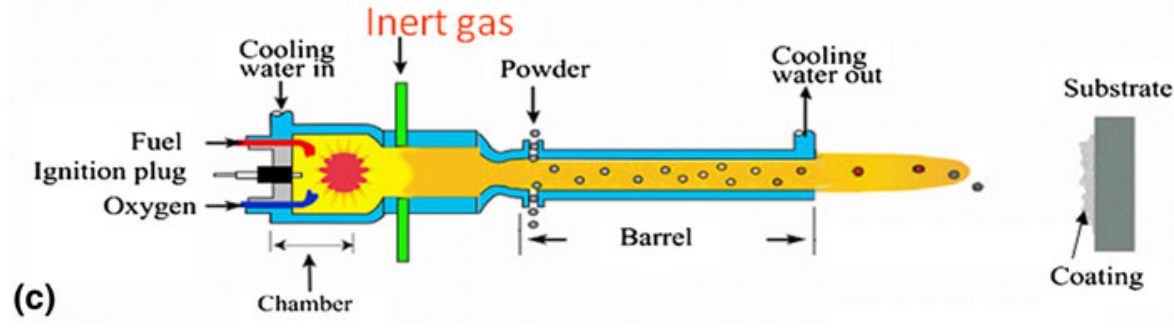

Fig. 3 Schematic of a commercially available HVOF gun (a), improvement with a gas shroud (b), and two-stage HVOF with a mixing chamber named as warm spray (c)

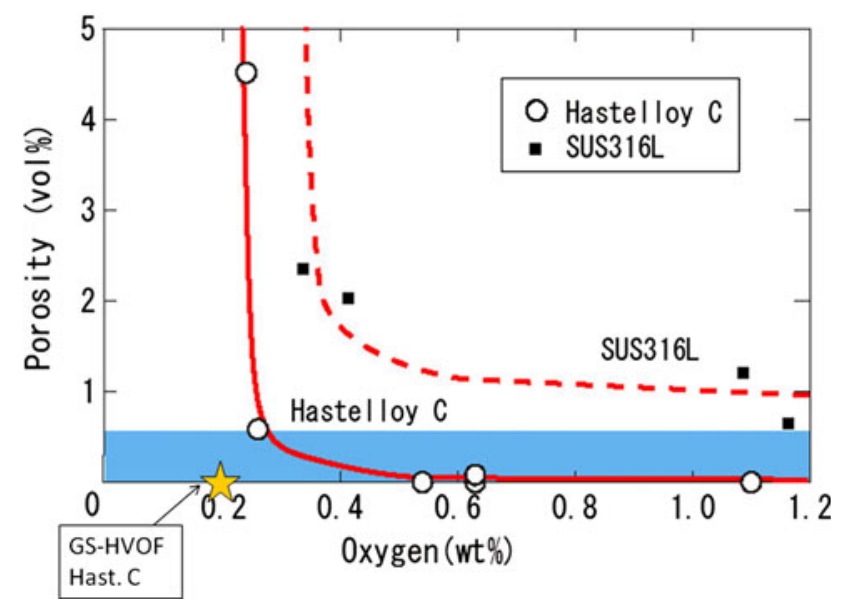

Fig. 4 Porosity vs. oxygen content of Hastelloy C and 316 stainless steel coatings fabricated by HVOF under various conditions. Two curves indicate trade-off relations between the two properties. The star plot indicates Hastelloy $\mathrm{C}$ coating made by the improved HVOF with a gas shroud

readily to become a mixture of oxides and nitrides through vigorous exothermic reaction. Therefore, more oxidation resistant alloys such as stainless steel $316 \mathrm{~L}$ and Hastelloy C 276 were chosen as the coating material. With these alloys, it was realized that there exists trade-off relationships between the porosity in the coatings and the oxygen contents in the coatings as shown in Fig. 4 (Ref 35-37). The curves in the figure indicate the limits of HVOF- sprayed deposits of 316L stainless steel and Hastelloy C. Porosity was measured by mercury intrusion porosimetry and oxygen was analyzed by the inert gas fusion technique. It was indicated that one cannot achieve highly dense coatings without increasing oxidation of the feedstock materials. Another important point is that the tradeoff curve is sensitive to the spray material. In the figure, one can see that with Hastelloy C it is relatively easy to eliminate pores that can be detected MIP (porosity below 0.3 vol. $\%$ ), whereas it is more difficult to achieve high density with $316 \mathrm{~L}$ stainless steel.

When these coatings were formed on carbon steel substrates and immersed in artificial seawater in laboratory, $316 \mathrm{~L}$ stainless steel coatings with $600 \mu \mathrm{m}$ were penetrated and exhibited significant amount of rusts on the coating surface after 3 days, which is the result of substrate corrosion through connected pores as shown in Fig. 5(a). Fe ions dissolved from the substrate surface traveled to the coating surface to form the rust where they meet with sufficient amount of oxygen. On the contrary, Hastelloy C coatings protected the steel substrate for periods longer than 3 months in laboratory even with the thickness of $200 \mu \mathrm{m}$ as shown in Fig. 5(b). When the coatings were tested in the natural marine environments, however, Hastelloy C coatings with $400 \mu \mathrm{m}$ thickness was penetrated after 3 months in the fully immersed zone as shown in Fig. 6(a). It was believed that the strong washing action by waves at the test site did not allow formation of corrosion product on the surface of very narrow through pores, if any, to slow down the corrosion reaction. 


\subsection{Gas-Shrouded HVOF and Marine Exposure Tests}

It was desired to improve the HVOF process to develop even denser and cleaner coatings and the shrouded HVOF was selected as an approach. There was already a report by Moskowitz about the effectiveness of a shrouded HVOF for corrosion problems in petrochemical plants but the detail of the process and the performance of such coatings in marine environments were not known (Ref 31, 38, 39). A gas-shroud attachment was developed at NIMS as shown in Fig. 3(b), where a tapered cylinder with two injection ports of nitrogen gas is attached to the barrel end in order to prevent the sprayed particles from

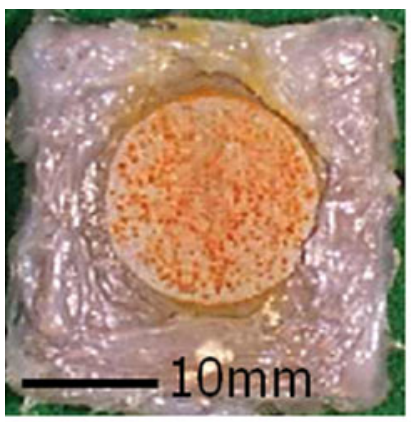

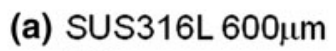
$72 \mathrm{hrs}$

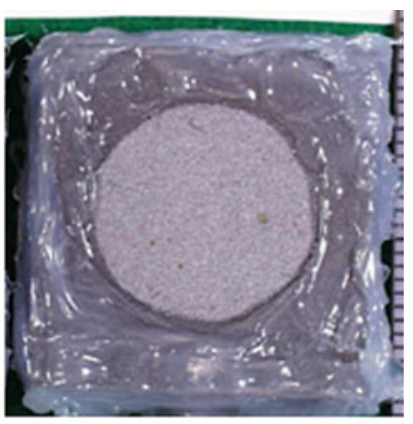

(b) Hastelloy $200 \mu \mathrm{m}$ 31days
Fig. 5 Surface appearance of HVOF-sprayed (a) SUS316L and (b) Hastelloy $\mathrm{C}$ coatings after immersion in artificial seawater in laboratory contacting with the ambient air (Ref 40, 41). In Fig. 7 are shown typical cross sections of Hastelloy coatings deposited by HVOF (a) and GS-HVOF (b), respectively. It is well known that the finely conjugated areas with darker contrast in the HVOF coatings composed of molten particles and oxygen concentration in these areas are high (Ref 42). As compared to this cross section, that of GS-HVOF appears to be much more uniform and clean. Actually, the oxygen concentration of the coating on the left was 0.52 mass \%, whereas that by GS-HVOF on the right was 0.20 mass \%. It is not possible, however, to tell which coating is denser and contain less through pores from the cross sections. Since it was highly desirable to judge the barrier capability of these coatings in laboratory before testing them in the natural environments, a method with high sensitivity was developed (Ref 43). A coated specimen was cut into a square of 20 by $20 \mathrm{~mm}$ and the coating surface of $10 \mathrm{~mm}^{2}$ was exposed, while other surfaces were coated with silicone resin. Then, the specimen was immersed into a $0.5 \mathrm{M} / \mathrm{dm}^{3} \mathrm{HCl}$ solution, which was sampled periodically for inspection by the inductively coupled plasma (ICP) mass spectroscopy. With this technique, it was possible to determine the dissolution rate of metal ions into the acid solution. As shown in Fig. 8, it was possible to detect the effects of coating thickness on the dissolution rate of $\mathrm{Fe}$ ions, which correspond to the decrease of through pores in the coatings. It should be noted that the vertical axis for the dissolution rate is logarithmic and corresponding corrosion rate in terms of thickness reduction rate is marked on the right vertical axis. Since the coating material Hastelloy $\mathrm{C}$ contains 5-6 mass $\%$ of $\mathrm{Fe}$, the detection limit shown by the dotted line

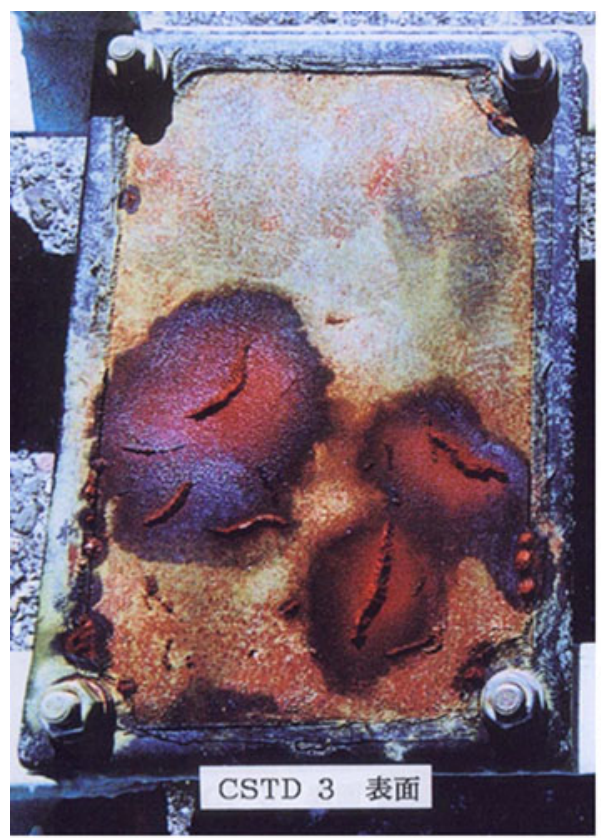

(a) Standard HVOF

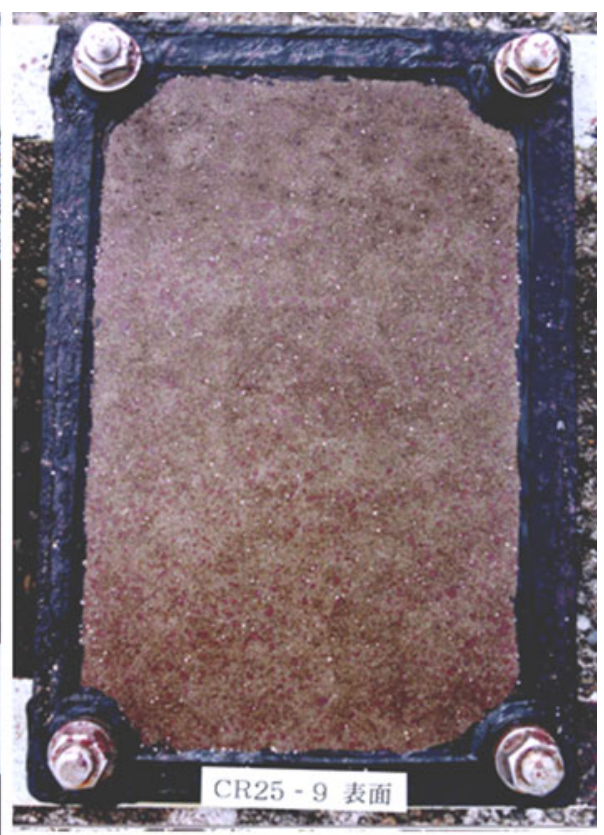

(b) GS-HVOF

Fig. 6 Surface appearance of Hastelloy C coatings formed on steel substrate tested for 3 months in seawater immersion: (a) standard HVOF and (b) HVOF with a gas-shroud attachment 


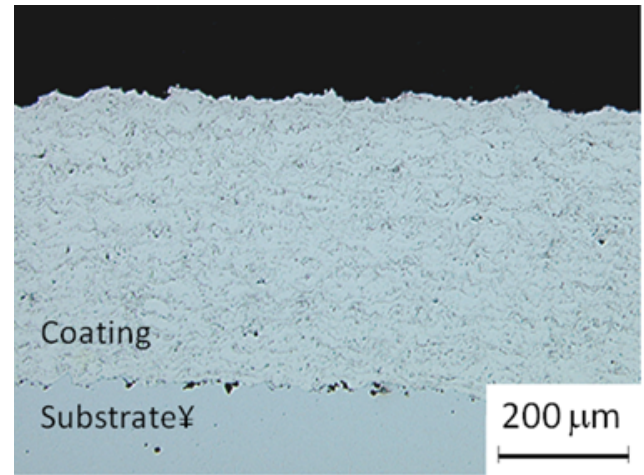

(a) HVOF

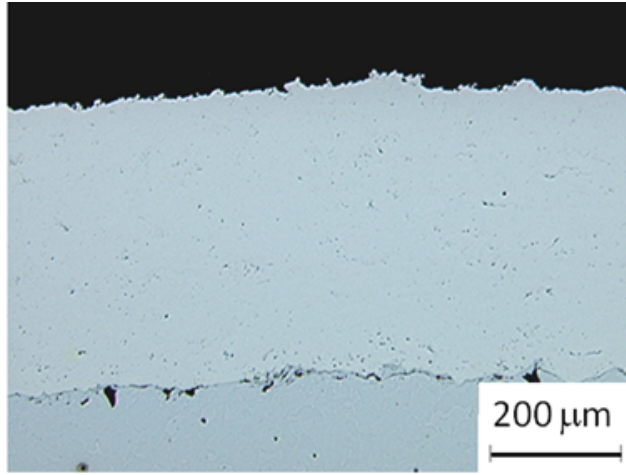

(b) GS-HVOF

Fig. 7 Cross sections of Hastelloy C coatings formed on steel substrate observed by optical microscopy: (a) standard HVOF and (b) $\mathrm{HVOF}$ with a gas-shroud attachment

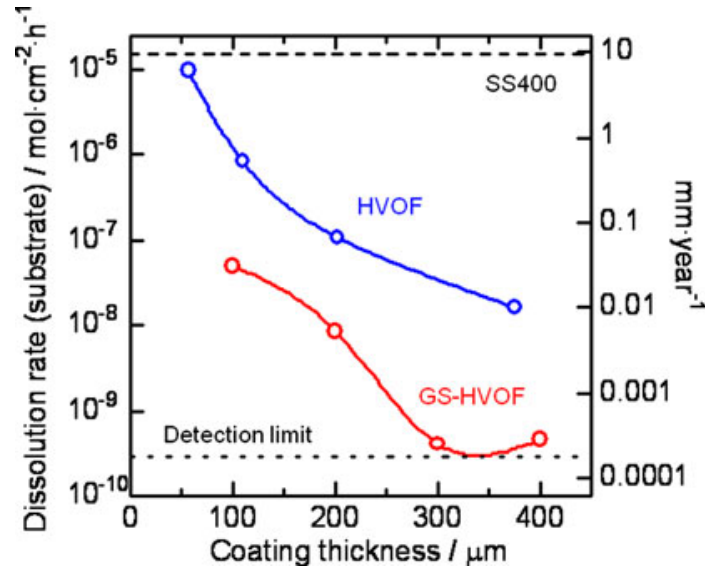

Fig. 8 Dissolution rate of iron ions from coating specimens of Hastelloy $\mathrm{C}$ with different thicknesses formed on carbon steel substrate. Specimens were immersed in $0.5 \mathrm{M} \mathrm{HCl}$ solution and the solution was sampled and measured by ICP (Ref 43)

in the figure is the rate recorded when a bulk plate of Hastelloy $\mathrm{C}$ with the same surface area was immersed in the test solution. It is clearly shown that from the specimen coated with $\mathrm{HVOF}$, significant amount of $\mathrm{Fe}$ dissolution is detected even with the coating thickness at $400 \mu \mathrm{m}$ whereas that from the GS-HVOF coating becomes comparable to the detection limit at $300 \mu \mathrm{m}$ thickness. Based on these results, Hastelloy $\mathrm{C}$ coatings with $400 \mu \mathrm{m}$ thickness were deposited on the two surfaces of steel plates of 300 by $400 \mathrm{~mm}$ size and have been tested in the marine exposure test sites. The coating protected the steel substrate in the immersed zone for 3 months as shown in Fig. 6(b), where the surface was covered with some seaweeds but the coating was intact. Summary of the test results for longer periods are shown in Fig. 9 in terms of the period till signs of corrosion were observed in the three test zones, i.e., splash, tidal, and immersed zones. The specimens included coatings made by the standard HVOF in the as-sprayed condition, in the polished condition and after heat treatment at $1273 \mathrm{~K}$ in vacuum for $1 \mathrm{~h}$ as well as these by GS-HVOF in the as-sprayed and

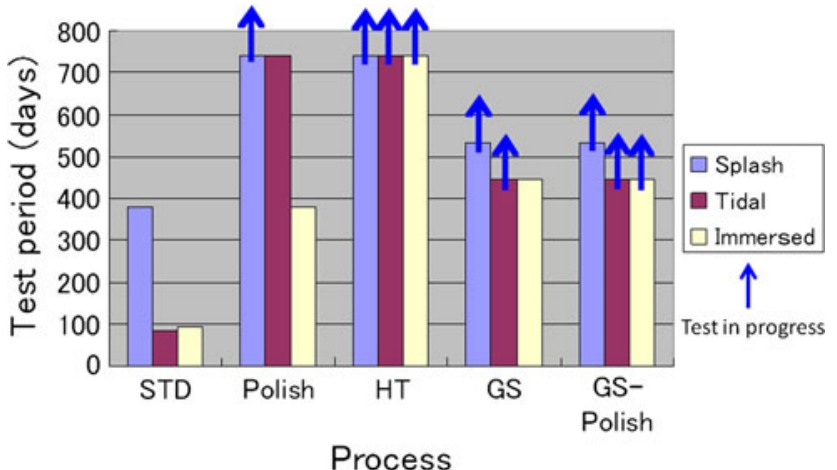

Fig. 9 Summarized results of marine exposure tests showing the periods till appearance of corrosion damage of HVOF-sprayed Hastelloy C coatings. STD: standard HVOF, Polish: polished standard HVOF, HT: heat-treated HVOF coating, GS: gasshrouded HVOF, GS-Polish: polished GS-HVOF coating. Test was conducted in the splash, tidal, and immersed zones

polished conditions. The arrows in the figure indicate that the tests are still in progress after about 2 years. As a general observation, GS-HVOF coatings have longer life than the standard HVOF coatings. Life is shortest in the immersed zone, followed by the tidal zone and then the splash zone. For bulk steels and alloys, it is well established that the corrosion rate in the splash zone is significantly higher than these in the other two zones because of the abundant supply of oxygen, water, and chlorides (Ref 44). The situation is totally different for these sprayed coatings because the most damaging reaction of water invasion through the connected pores and substrate dissolution take place during the wetted time. It should be noted that surface polishing has an effect to extend the life of these coatings at least by a factor of two. Heat treatment was remarkably effective because it closes the connected pores and homogenizes the coating microstructure. Such heat treatment, however, is not applicable to large structures and many substrate materials do not allow the treatment due to their lower melting points or destruction of the controlled microstructure. 
Unfortunately, the efforts in this project did not result in successful fabrication of reliable pore-free barrier coatings. Serious criticism against this type of technology nested in the fact that if such coating should be penetrated either by poor quality control during fabrication or unpredicted mechanical damage, the coating-substrate interface will be preferentially corroded due to the galvanic coupling between the noble coating and the less noble steel substrate and will result in fatal debonding of the coating over the entire area in a relatively short time.

Nevertheless several lessons were obtained:

(1) The combustion gas jet in HVOF is too reactive to spray reactive metals such as titanium.

(2) Even though one can find inferior coatings for corrosion protection rather easily by various testing methods, it is not easy to characterize coating which has a long service life in marine environment in the unit of years.

(3) Classical metallographic preparation is not effective to find through pores detrimental to the service life of coatings made by high-velocity thermal spray processes such as HVOF.

In order to facilitate spraying of more reactive metals such as titanium, another modification of HVOF has been developed as shown in Fig. 3(c). A mixing chamber was inserted in between the combustion chamber and the powder feed ports in order to mix the combustion gas with room temperature nitrogen gas so that the gas temperature and composition at the powder injection position can be controlled in a wide range. This two-stage HVOF has been named as "warm spray" as its process characteristics occupy a position between HVOF and CS as discussed in more detail in the next section. It must be noted here that lowering of the gas temperature of HVOF spray by mixing the combustion gas jet in the expanded supersonic region with a room temperature gas or water mist was patented by Browning (Ref 45). He also patented the idea of spraying powder particles below the melting point but sufficiently higher temperature to soften the material substantially (Ref 46). The warm spray process by the present authors is essentially based on the same concept but the gas mixing is achieved before the expansion into a supersonic jet, which is known to be much more effective (Ref 47).

\section{Process Characteristics of Warm Spray}

\subsection{Numerical Simulation of Warm Spraying and Comparison With Other Processes}

There are several diagnostic devices for measuring the temperature and velocity of sprayed particles. Another useful approach is numerical simulation because it can analyze flow fields and particle behavior inside the spraying apparatus, thereby saving much of the time and cost needed for experiments. In this section, the method and results of the numerical simulation of the WS process, as well as that of the HVAF process for comparison, are described.

In the following calculations of combustion and mixing, nine gas species $\left(\mathrm{CO}, \mathrm{CO}_{2}, \mathrm{H}_{2} \mathrm{O}, \mathrm{H}_{2}, \mathrm{H}, \mathrm{OH}, \mathrm{O}_{2}, \mathrm{O}\right.$, and $\mathrm{N}_{2}$ ) which follow the equation of state were included (Ref 10). The fuel (kerosene) was assumed to be fully burnt and no hydrocarbons were present in the mixture. In addition, the product gases were assumed to be fully mixed in the combustion chamber and the mixing chamber to reach chemical equilibrium state. The gas temperature and mole fractions of each species in the chemical equilibrium state were calculated by software called chemical equilibrium with applications (Ref 48). In this section, the equivalence ratio $\varphi$ was set at 1 for all the calculations except for Fig. 13(c).

Figure 10(a) shows a typical set of operating conditions, as well as the calculated pressure in the mixing chamber $p_{03}$, for the WS gun. The mixing ratio of kerosene to oxygen was set at the stoichiometric ratio for complete combustion. The flow rates of kerosene and oxygen had to be reduced as the nitrogen flow rate increased owing to the increase in the pressure within the combustion

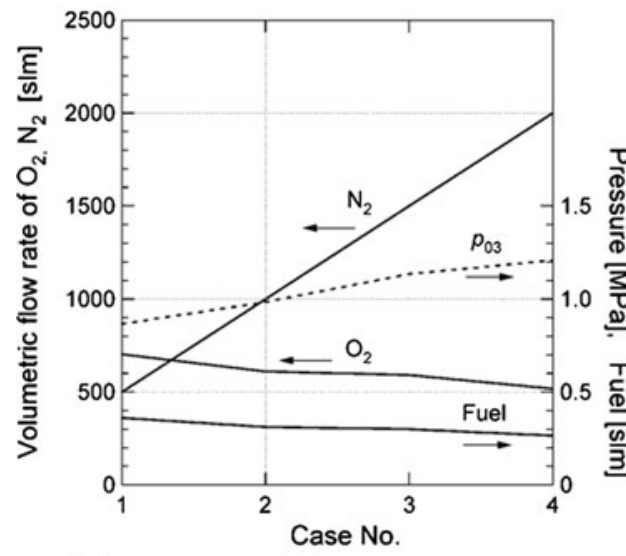

(a) Warm Spray

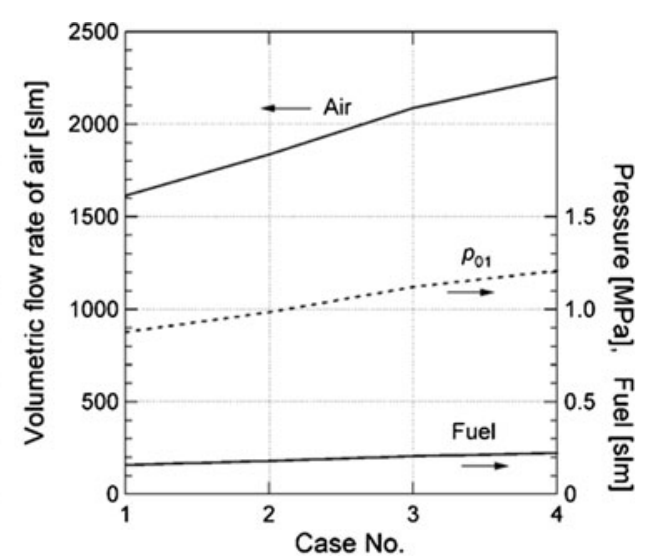

(b) HVAF

Fig. 10 Operating conditions of warm spray (a) and HVAF (b) used for numerical simulation 
chamber. The pressure in the combustion chamber is slightly above the pressure in the mixing chamber $p_{03}$ shown in Fig. 10(a). The gas temperature in the mixing chamber obtained by the chemical equilibrium calculation varied from 2740 (Case 1) to $1780 \mathrm{~K}$ (Case 4). Figure 10(b) shows a spray condition of an imaginary HVAF gun with the same geometry of the C-D nozzle and the barrel as the WS gun. The mixing ratio of kerosene to air was again set at the stoichiometric ratio, and their flow rates are adjusted so that the pressure in the combustion pressure $p_{01}$ of the HVAF gun becomes the same values as $p_{03}$ in Fig. 10(a). The gas temperature in the combustion chamber of the HVAF gun was calculated as $2250 \mathrm{~K}$ for Cases 1-4. After obtaining the stagnant gas conditions just upstream of the C-D nozzle for both the WS and HVAF guns, quasi-one-dimensional gas dynamics model (Ref 48) was used for the region inside the spray apparatus, which starts from the entrance of the C-D nozzle to the exit of the barrel. Outside the barrel, semi-empirical equations (Ref 49) were used to calculate the gas velocity and temperature of the gas jet along the center line.

\subsection{Gas and Particle Flow Field}

For the WS gun, the gas velocity and temperature field from the nozzle to the barrel exit was calculated by integrating Eq 1-4, which take into account the change in the cross-sectional area of the gun, the pipe friction in the barrel, and the heat transfer (heat loss to the cooling water) through the inner wall of the barrel. The heat loss to the cooling water was determined experimentally by measuring the flow rate and the temperatures of the water at the inlet and outlet of the apparatus. The heat loss to the cooling water varied from 80 to $110 \mathrm{~kW}$ depending on the operating condition while the total power generated by the combustion was approximately $200 \mathrm{~kW}$. The cooling rates (Ref 10) of the combustion chamber and the mixing chamber were set constant at 0.20 and 0.14 (Ref 14), respectively, based on the measurement of the heat loss. The cooling rate of the barrel varies depending on the flow rate of the nitrogen gas and was calculated by an

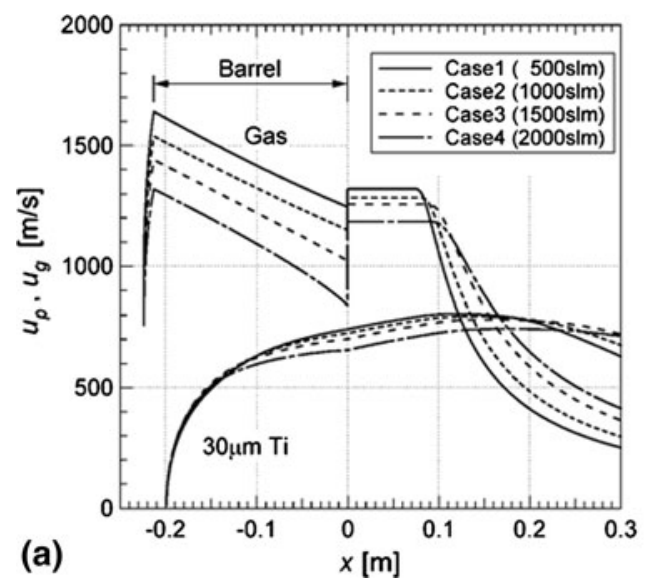

Fig. 11 Gas/particle velocity of (a) WS gun and (b) HVAF gun empirical equation derived from the experiment. As for the HVAF, the gun was assumed to be air-cooled with the cooling rate of 0.05 for the combustion chamber and that of 0.036 for the barrel.

$$
\frac{d u_{\mathrm{g}}}{d x}=\frac{u_{\mathrm{g}}}{\left(M_{\mathrm{g}}^{2}-1\right)} \frac{d A}{A d x}-\frac{u_{\mathrm{g}}}{\left(M_{\mathrm{g}}^{2}-1\right)}\left(\frac{\gamma M_{\mathrm{g}}^{2}}{2} \frac{4 f}{d}-\frac{\gamma-1}{\gamma R T_{\mathrm{g}}} \frac{\delta q}{d x}\right)
$$

$\frac{d \rho_{\mathrm{g}}}{d x}=-\rho_{\mathrm{g}}\left(\frac{1}{u_{g}} \frac{d u_{\mathrm{g}}}{d x}+\frac{1}{A} \frac{d A}{d x}\right)$

$\frac{d T_{\mathrm{g}}}{d x}=\frac{\gamma-1}{\gamma R}\left(-\frac{\delta q}{d x}-u_{\mathrm{g}} \frac{d u_{\mathrm{g}}}{d x}\right)$

$p=\rho_{\mathrm{g}} R T_{\mathrm{g}}$

where $x$ is the axial direction, $u_{\mathrm{g}}$ is the gas velocity, $M_{\mathrm{g}}$ is the gas Mach number, $A$ is the cross-sectional area, $\gamma$ is the specific heat ratio, $f$ is the friction factor, $d$ is the barrel diameter, $R$ is the gas constant, $q$ is the heat loss per unit mass of gas, $\rho_{\mathrm{g}}$ is the gas density, $T_{\mathrm{g}}$ is the gas temperature, and $p$ is the static pressure.

Semi-empirical equations (Ref 49) were used to calculate the gas velocity and temperature along the center line outside the barrel. The under- and over-expansion of the jet flow were also modeled as a stepwise change in the gas velocity and temperature at the barrel exit by introducing the fully expanded jet Mach number (Ref 50), as will be shown later in Fig. 11 and 12. The gas velocity and temperature in the potential-core (Ref 51) region of the jet were set at constant values which are calculated by the fully expanded jet Mach number. Once the gas flow filed $u_{\mathrm{g}}(x)$ and $T_{\mathrm{g}}(x)$ is obtained, the acceleration and heating of a spherical particle injected at the powder feed ports can be expressed by the following two equations (5) and (6). The velocity and temperature of one particle along the center line were obtained by integration of these equations

$m_{\mathrm{p}} \frac{d u_{\mathrm{p}}}{d t}=\frac{1}{2} C_{\mathrm{d}} \rho_{\mathrm{g}}\left(u_{\mathrm{g}}-u_{\mathrm{p}}\right) \cdot\left|u_{\mathrm{g}}-u_{\mathrm{p}}\right| \frac{\pi}{4} d_{\mathrm{p}}^{2}$

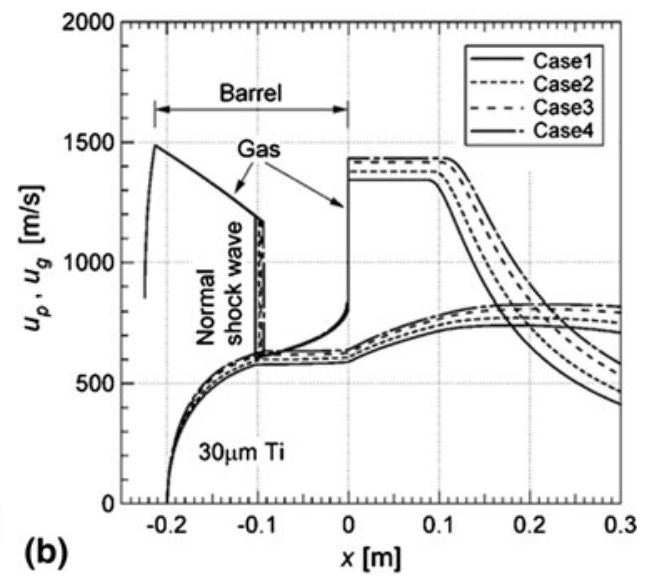

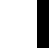




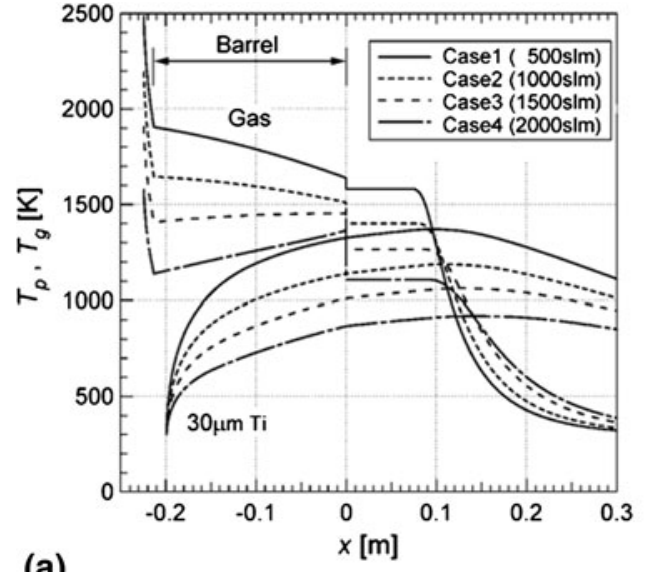

(a)

Fig. 12 Gas/particle temperature of (a) WS gun and (b) HVAF gun

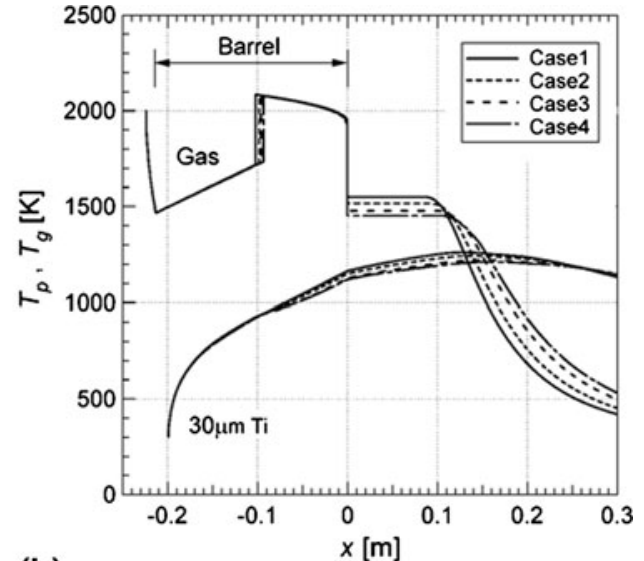

(b)
$\mathrm{Nu}=2+0.6 \operatorname{Re}^{0.5} \operatorname{Pr}^{0.33}$

where $t$ is the time, $m_{\mathrm{p}}$ is the particle mass, $u_{\mathrm{p}}$ is the particle velocity, $C_{\mathrm{d}}$ is the drag coefficient, $d_{\mathrm{p}}$ is the particle diameter, $C_{\mathrm{p}}$ is the specific heat of particle, $T_{\mathrm{p}}$ is the particle temperature, $\mathrm{Nu}$ is the Nusselt number, $k_{\mathrm{g}}$ is the gas thermal conductivity, $\mathrm{Re}$ is the Reynolds number, $\mathrm{Pr}$ is the Prandtl number. In order to calculate the Re and Pr, the specific heat ratio at constant pressure, thermal conductivity, and viscosity of the combustion-mixed gas are required. These thermal properties for each gas species, as well as the averaged properties, were calculated by the equations proposed in Ref 52. The gas density, which is necessary to calculate the Re, was obtained by Eq 4 . When numerically integrating Eq 5 and 6, the variable $t$ was transformed to $x$. Then, the transformed equations (Ref 48) were numerically integrated in $x$-direction with the step size $\Delta x=0.1 \mathrm{~mm}$, which was found to be sufficiently small to obtain solutions almost independent of the step size.

\subsection{Model Results}

Figure 11(a) shows the calculated gas velocity and the velocity of a $30 \mu \mathrm{m}$ diameter titanium powder injected at the powder feed port for the WS gun. Here, distance $x=0$ corresponds to the barrel exit of the nozzle and the powder feed ports are situated about $0.2 \mathrm{~m}$ upstream. As the gas expands through the C-D nozzle, its velocity increases rapidly and then decreases gradually along the barrel length due to friction with the inner wall of the barrel. Outside the barrel, the gas velocity increases stepwise, which represents the under-expansion of the jet flow at the barrel exit, and it remains constant in the potential-core region outside the barrel, and then decreases again due to mixing with the ambient air. It should be noted that the gas velocity is higher with less nitrogen flow rate through the gun and the potential-core region of the jet. This is mainly due to the higher gas temperature in the barrel and jet. This can be explained by the effect of nitrogen flow rate on the speed of sound and Mach number of the mixed gas; (1) less amount of mixing of nitrogen at room temperature means a higher gas temperature (larger speed of sound) in the mixing chamber, as well as in the barrel, (2) although the supersonic flow entering the barrel (about Mach 2.0 regardless of the nitrogen flow rate) is decelerated by the pipe friction in the barrel, a higher-temperature gas flow, from which more heat is transferred to the water-cooled barrel, results in less decrease in Mach number in the flow direction due to the effect of supersonic Rayleigh flow (Ref 53). Since the gas velocity is obtained by a multiplication of the speed of sound and the Mach number, the less nitrogen flow case shows a larger gas velocity in the barrel and barrel exit. It is very interesting to see that the velocity profiles of the $\mathrm{Ti}$ particle are almost unaffected by the nitrogen flow rate. This is attributed to the increase in the gas density by addition of nitrogen, which compensated the decreased gas velocity.

Figure 11(b) shows the calculated gas velocity and the velocity of a $30 \mu \mathrm{m}$ diameter titanium powder for the HVAF gun. The gas velocity at the inlet of the barrel is $1500 \mathrm{~m} / \mathrm{s}\left(M_{\mathrm{g}}=2.0\right)$, which is almost the same as that for Case 2 of the WS gun. However, the gas decreases more rapidly after entering the barrel as compared to the WS gun, due to a larger decelerating effect by the pipe friction against the acceleration effect of cooling. Because of this, the gas flow cannot maintain a supersonic flow until the end of the barrel, causing a normal shock wave in the barrel at around $x=-0.1 \mathrm{~m}$ for all the four cases. As a result, subsonic flow region appears between the normal shock wave and the barrel exit, where the gas flow is "choked" $\left(M_{\mathrm{g}}=1\right)$ generating under-expanded sonic jets. It is interesting to note that the maximum particle velocity 
of the HVAF gun is roughly the same as that of the WS gun.

Figure 12(a) shows the significant effect of mixing nitrogen on the temperature of the mixed gas and particles. The gas temperature steeply decreases due to expansion through the C-D nozzle and then gradually decreases for Cases 1-2 and increases for Cases 3-4 in the barrel depending on the extent of the heat loss to the water-cooled through the barrel against the temperature recovery due to the deceleration of the gas flow by pipe friction. After exiting the barrel, the gas temperature remains constant in the potential-core region of the jet, and finally decreases again due to mixing with the ambient air. In summary, the numerical simulation shows that the particle temperature at $x=0.2 \mathrm{~m}$, where substrates are normally placed for the WS process, can be changed from 1250 to $900 \mathrm{~K}$ while keeping its velocity relatively unchanged.

Figure 12(b) shows the simulated gas/particle temperatures for the HVAF gun. As can be seen in the figure, hot gas region appears between the normal shock wave and the barrel exit. This is due to the result of the energy conversion from the decreased kinetic energy of the gas flow to the increased thermal energy. Since the distributions of the gas temperature are almost unaffected through Cases 1-4, the profiles of the particle temperature also does not largely change.

Figure 13 shows the summary of the variation of the particle temperature against the particle velocity starting from the powder injection port $\left(u_{\mathrm{p}}=10 \mathrm{~m} / \mathrm{s}, T_{\mathrm{p}}=300 \mathrm{~K}\right)$ to the outside of the gun at $x=0.3 \mathrm{~m}$ for the WS and HVAF guns. Four solid circles plotted on the curves show the particle conditions at the barrel exit $(x=0)$. From Fig. 13(a), the overall trend of the particle condition for the WS gun is that the particle temperature and velocity increases at almost the same rate, showing rather linear increase from the powder injection port to the location where the maximum particle velocity is reached outside of the gun. The maximum particle temperature can be decreased from 1400 to $900 \mathrm{~K}$ by increasing the nitrogen flow rate from 500 to $2000 \mathrm{slm}$. The overall temperature range of the particle outside of the gun $(x=0-0.3 \mathrm{~m})$, where a substrate can be situated, for Cases 1-4 is about $850-1400 \mathrm{~K}$. The corresponding velocity range of the particle is about $620-800 \mathrm{~m} / \mathrm{s}$. As for the HVAF gun in Fig. 13(b), the particle temperature linearly increases in the range of the particle velocity of $0-600 \mathrm{~m} / \mathrm{s}$. Then, the particle temperature increases to about $1100 \mathrm{~K}$, while the gas velocity remains constant at about $600 \mathrm{~m} / \mathrm{s}$. The overall ranges of the particle temperature and velocity
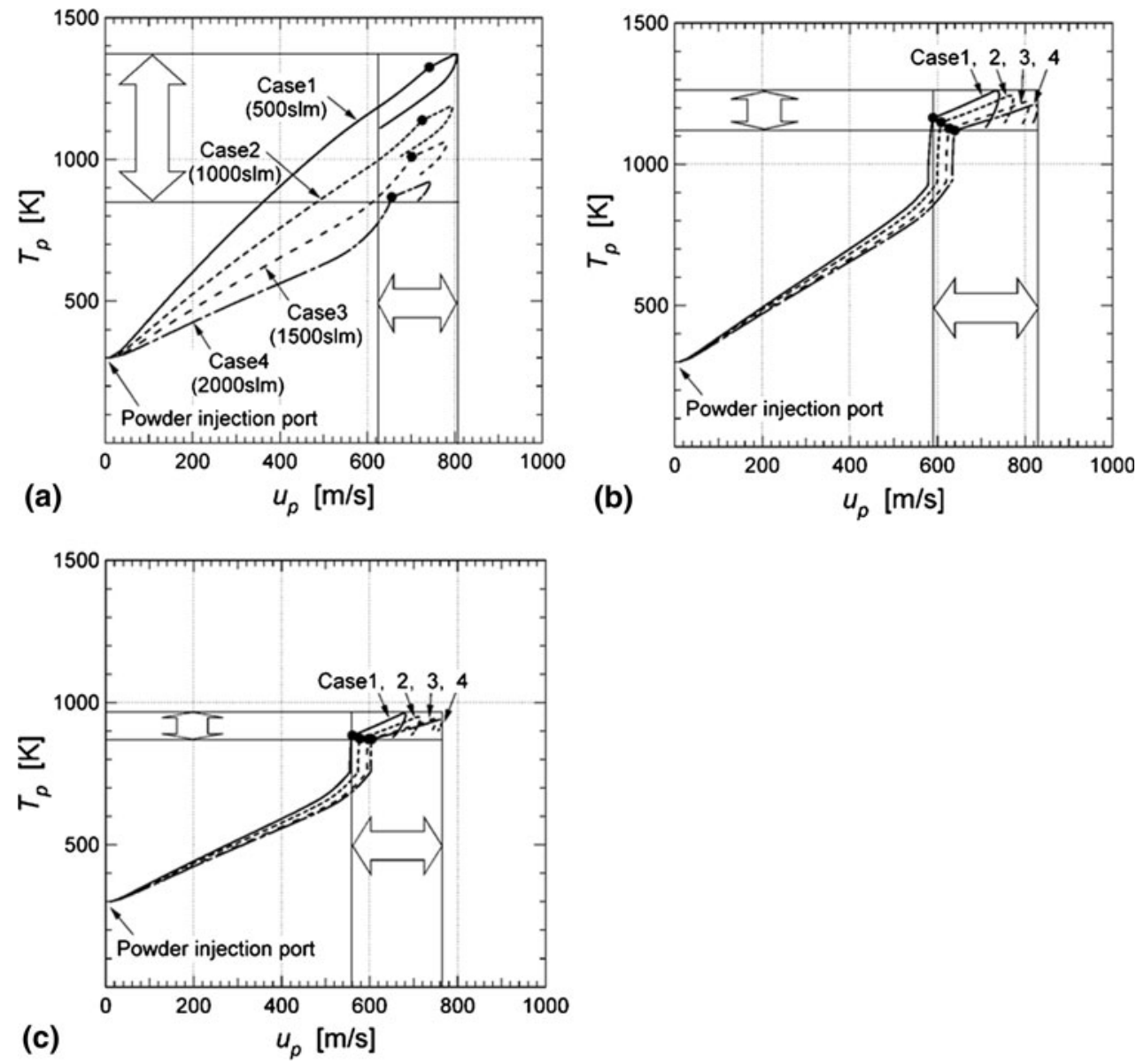

Fig. 13 Temperature-velocity trajectories of $30 \mu \mathrm{m}$ Ti particles sprayed by (a) WS gun, (b) HVAF gun, and (c) HVAF gun ( $\varphi=0.69$ ) 
outside the gun are $1100-1300 \mathrm{~K}$ and $600-840 \mathrm{~m} / \mathrm{s}$, respectively. Therefore, it can be said about the WS by comparing the HVAF that the particle velocity of the WS is comparable to HVAF, however, the controllable range of the particle temperature is about three times wider for the WS compared to HAVF under the present numerical conditions, including the stoichiometric mixture of kerosene and air for complete combustion. The range of the particle temperature of the HVAF will be extended to a lower value if the gun is operated at fuel-lean/rich conditions within the limit of stable combustion.

Figure 13(c) shows the simulated gas/particle temperatures for the HVAF gun under fuel-lean equivalence ratio $(\varphi=0.69)$. This figure shows that if the HVAF gun is operated at $\varphi=0.69$, the gun can provide as lower particle temperature as the WS gun operated at Case 4 condition shown in Fig. 13(a), while keeping the particle velocity

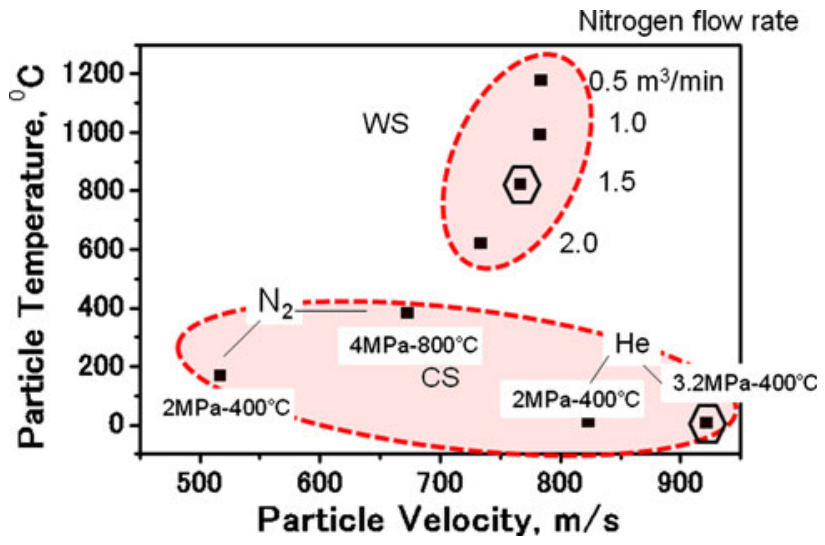

Fig. 14 Process map showing the ranges of particle temperature and velocity achievable by warm spray and cold spray for titanium particles with $30 \mu \mathrm{m}$ diameter. Plots represent the results of numerical simulation for the conditions used in the experiments. Two hexagonal marks indicate conditions under which splat specimens for TEM analysis were prepared almost unchanged from Fig. 13(b). Although the particle temperature sprayed by the HVAF gun can be lowered when the gun is operated at fuel-lean condition, the lower limit of the particle temperature directly depends on the lower limit of $\varphi$ to generate stable combustion. In addition, the upper limit of the particle temperature of the HVAF gun can hardly be extended from Fig. 13(b). On the other hand, the WS gun is capable of extending the upper/lower limits of the particle temperature from Fig. 13(a) by decreasing/increasing the flow rate of nitrogen gas.

\section{Microstructure and Mechanical Properties of WS Metallic Coatings}

Microstructure and mechanical properties of WS coatings have been investigated (Ref 4, 6-9, 12, 15, 17, 19, 20) for materials such as titanium, copper, aluminum, metallic glass, WC-Co cermet, nano-grain titanium oxide, UHMW-PE, and PEEK. Among them, titanium and WC-Co have been most extensively studied due to their potential application importance and sensitivity to thermal degradation.

Figure 14 shows typical ranges of velocity and temperature of sprayed titanium particles $(30 \mu \mathrm{m}$ diameter $)$ at the substrate position for both warm and CS as calculated by numerical simulation in the previous section. The plots indicate specific conditions at which coatings were prepared for characterization as shown in Fig. 15. For warmsprayed coatings, it can be seen that the coating at $500 \mathrm{slm}$ of nitrogen flow rate contains significant oxide at the particles' boundaries, the coatings formed at higher nitrogen flow rate become cleaner but at $2000 \mathrm{slm}$, it becomes highly porous. For CS coatings, the coatings are porous with the two nitrogen conditions but it becomes very dense with $\mathrm{He}$ as the propellant gas due to the higher impact velocity (Ref 25). Splats formed under the two
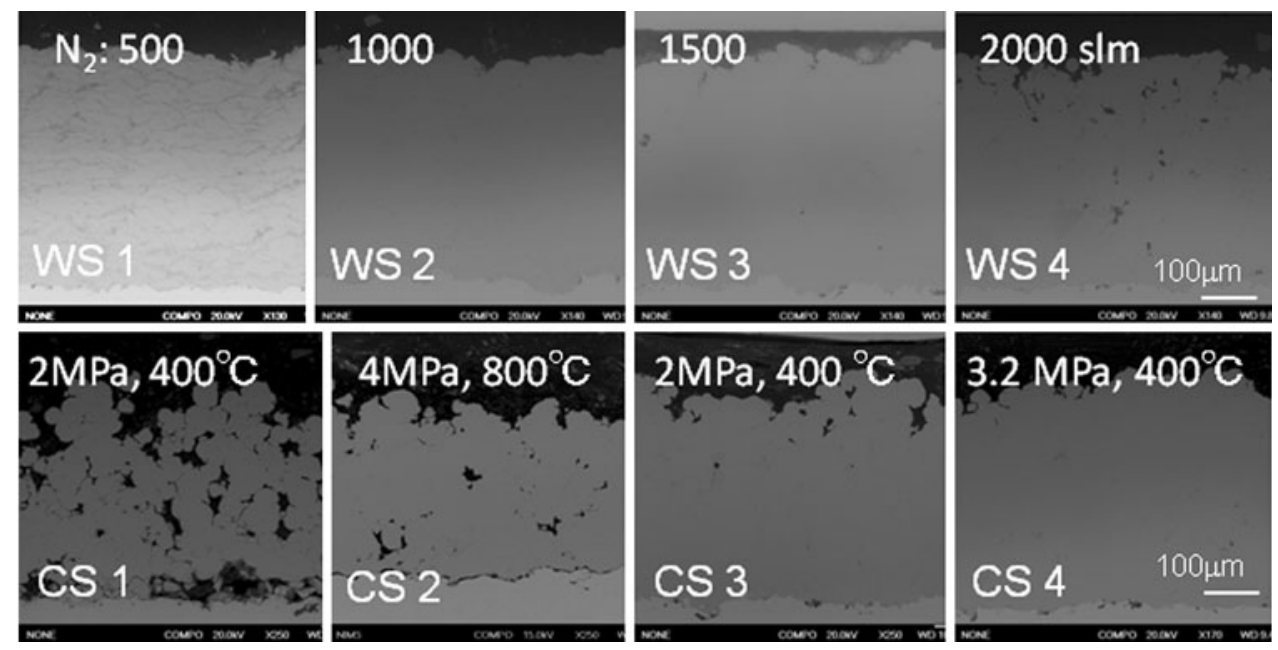

Fig. 15 Cross sections of warm sprayed and cold sprayed titanium coatings deposited with conditions corresponding to the plots in Fig. 14 observed by SEM 


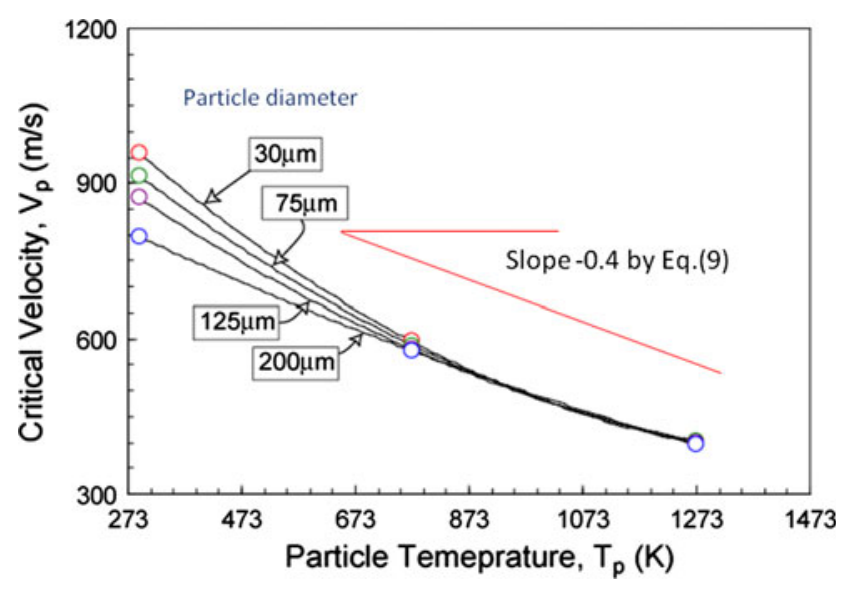

Fig. 16 Temperature effect on the critical velocity of Ti particles by numerical impact simulation ( Ref 3$)$. Slope -0.4 is given in Eq 9 by Assadi et al

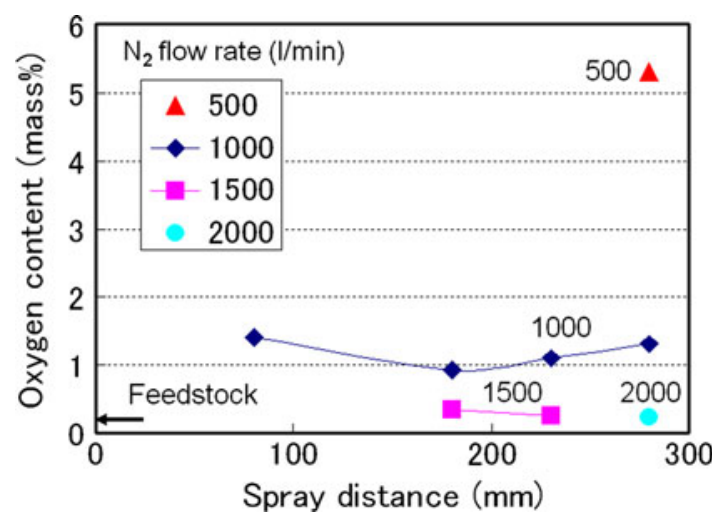

Fig. 17 Oxygen contents in warm sprayed titanium deposits formed under various nitrogen flow rates and spray distances (Ref 2)

conditions marked in Fig. 14 were investigated in more detail.

Figure 16 shows the dependence of the critical velocity $V_{\text {cr }}$ necessary to cause adiabatic shear instability on the particle temperature, which was obtained by the FEM simulation of a spherical particle onto a substrate (Ref 3 ). Since thermal conduction was taken into account in the simulation, there appeared some size dependence in the lower temperature regime. As a rough measure of the temperature effect, a line with slope of -0.4 is drawn on the figure, which implies that a temperature rise by $400 \mathrm{~K}$ is equivalent to a reduction of critical velocity by $160 \mathrm{~m} / \mathrm{s}$. This coefficient is in agreement with the Eq 9 proposed in a paper by Assadi et al. (Ref 27)

$V_{\text {cr }}=667-14 \rho+0.08 T_{\mathrm{m}}+0.1 \sigma_{\mathrm{u}}-0.4 T_{\mathrm{i}}$,

where $\rho$ is the density $\left(\mathrm{g} / \mathrm{cm}^{3}\right), T_{\mathrm{m}}$ is the melting point $\left({ }^{\circ} \mathrm{C}\right), \sigma_{\mathrm{u}}$ is the yield stress $(\mathrm{MPa})$, and $T_{\mathrm{i}}$ is the particle temperature $\left({ }^{\circ} \mathrm{C}\right)$.

The oxygen contents of the WS Ti coatings analyzed by the inert gas fusion method are shown in Fig. 17

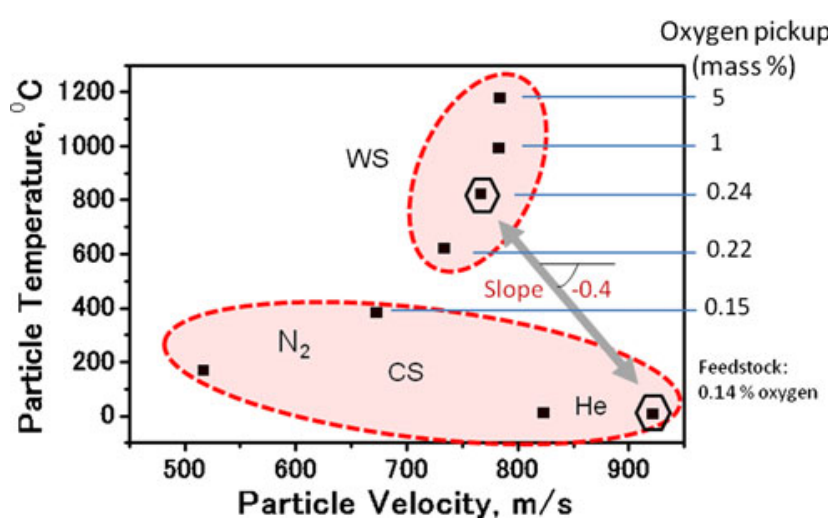

Fig. 18 Modified process map based on Fig. 14, onto which oxygen contents of titanium coatings and the slope of -0.4 relating temperature to velocity are superposed. Two hexagonal marks indicate conditions under which splat specimens for TEM analysis were prepared

for various nitrogen flow rates and spray distances (Ref 2, 5). The oxygen level in the feedstock powder was 0.14 mass \%, which increased significantly to 5.5 mass $\%$ when the nitrogen flow rate was $500 \mathrm{slm}$. As the nitrogen flow rate increased from 500 to $1000 \mathrm{slm}$, it decreased significantly and became $<1 \%$ at the distance of $180 \mathrm{~mm}$. At shorter distances, it is believed that oxidation increased due to the overheating of the coating surface by the WS hot gas during spraying, whereas it increased due to a longer traveling distance in the air. The decrease in the oxygen content is caused by the lower flame temperature. At a flow rate of $2000 \mathrm{slm}$, the oxygen content decreased further to 0.22 mass \% but the coating became highly porous as shown in Fig. 15.

Analysis of titanium deposition by WS and CS are shown in Fig. 18 in the form of process map. On the righthand side of the map, oxygen levels acquired by each spray condition in WS and CS by nitrogen are shown. In $\mathrm{CS}$, it is possible to achieve coatings with oxygen level as low as 0.15 mass \%, whereas the minimum value achieved by WS is 0.22 . If a coating with oxygen level $<0.2 \%$ is required, it is not advisable to use WS and CS should be used. Since titanium is highly reactive with oxygen at the processing temperature of WS, it is readily expected that the amount of oxidation will be significantly less for more oxidation resistant alloys based on other elements such as iron, nickel, copper, and cobalt. Another point to be noted is the gray arrow with a slope of -0.4 connecting the two marked spray conditions selected for WS and CS. When the cross sections of these coatings shown in Fig. 15 are compared, their resemblance in terms of coating density is consistent with the discussion concerning critical velocity, although the barrier capability of such coatings in corrosive environments cannot be judged from such microstructures as discussed in section 2.3.

\subsection{Titanium Splats}

A typical WS titanium splat deposited on a medium carbon steel substrate is shown in Fig. 19(a) top view and

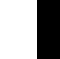



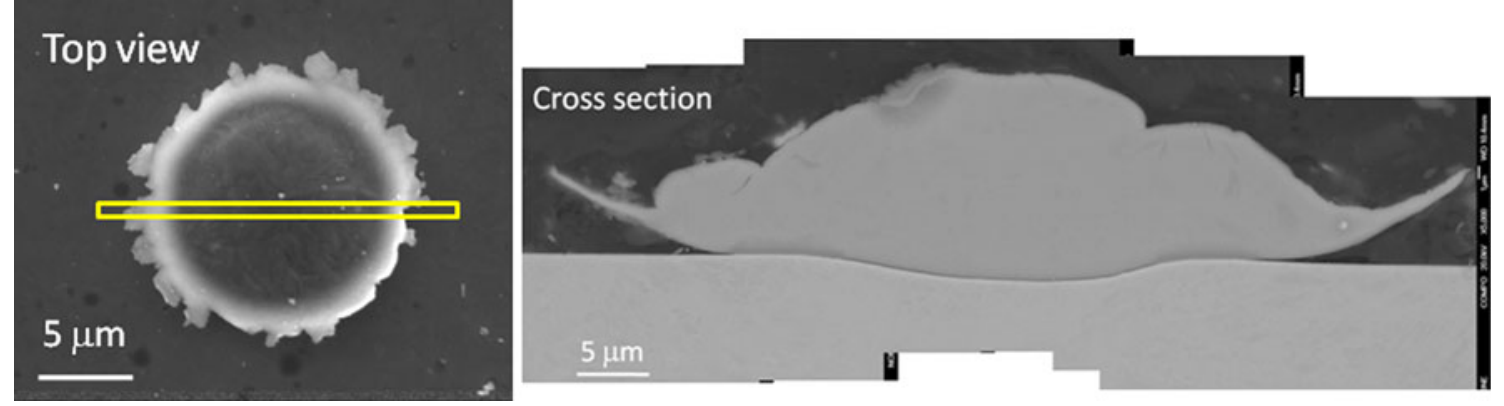

Fig. 19 Top view and cross section of a titanium particle (splat) deposited onto steel substrate under the WS condition with 1500 slm

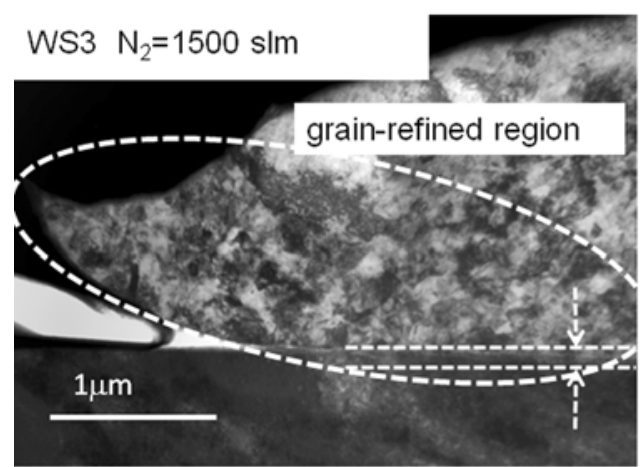

(a)

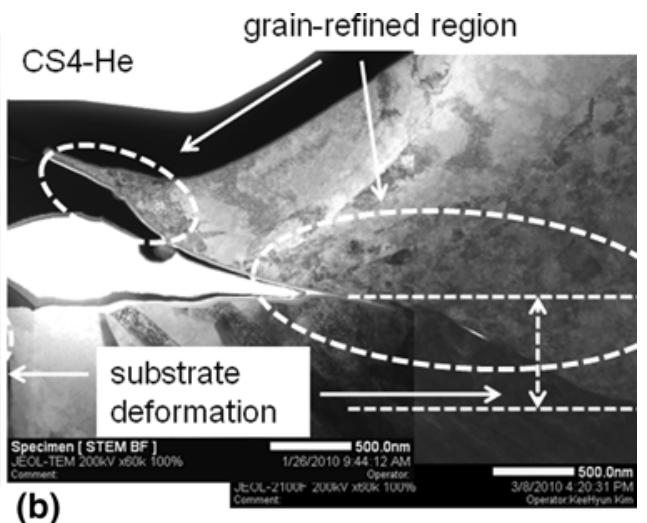

(b)

Fig. 20 TEM images of cross section of titanium splats (a) by warm spraying and (b) by cold spraying, showing regions of grain refinement and substrate deformation

(b) cross section, for which the operating condition of WS was Case 3 in Fig. 10(a). Titanium splats were also prepared by cold spraying under various conditions as shown in Fig. 14 and thin foil specimens for TEM observation have been cut out from the highest-velocity condition using $\mathrm{He}$ as shown in Fig. 14. In Fig. 20, comparison of the internal microstructure of the WS splat with CS splat is shown. Two characteristics are clearly seen from the figure, i.e., the degree of substrate deformation by the impact is more pronounced for the CS splat than WS due to the higher impact velocity and lower temperature of the titanium particle. Another point is that grain refinement due to dynamic recrystallization took place in a much larger volume in the WS splat as compared to CS. The original grain size of the feedstock powder is about a few $\mu \mathrm{m}$, whereas the grain size was reduced to a few tens of nm after impact. For the rotational grain refinement to happen, the material needs to be at a high enough temperature for dislocations to move and needs to undergo severe plastic deformation (Ref 6). Schematic of grain refinement is shown in Fig. 21. WS particle satisfies these conditions largely in the lower portion of a particle.

Another important aspect of splat characterization is bonding. Already a number of literatures have suggested that the splat-substrate interface consists of a poorly bonded or often unbonded region around the south-pole of an impacted particle and a well-bonded region surrounding the south-pole. It is believed that severe shear

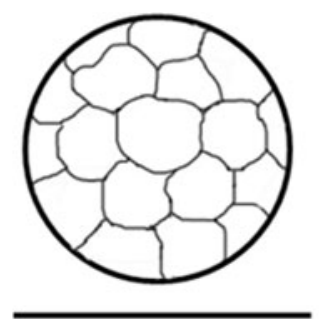

(a) spraying

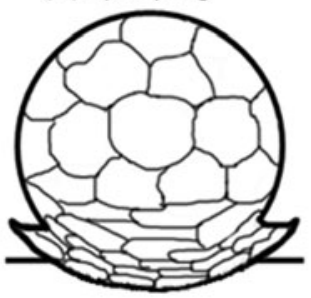

(c) elongation \& breaking-up of subgrains

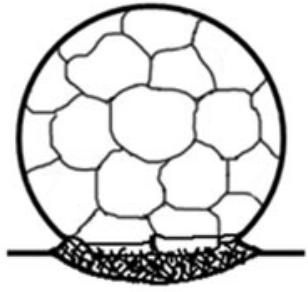

(b) tangle of dislocation

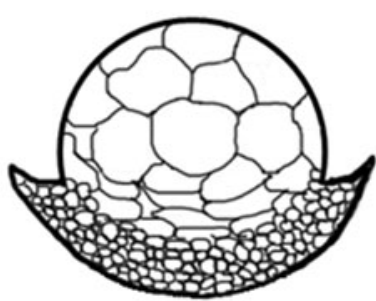

(d) final shape
Fig. 21 Schematic evolution of grain refinement by dynamic recrystallization: (a) spraying titanium particle onto the substrate, (b) entanglement of dislocations, (c) formation of dislocation cells (and subgrains) and re-elongation, and (d) breaking-up, rotation and recrystallization of subgrains by thermal softening effects enough to trigger the viscous flow (Ref 6) 


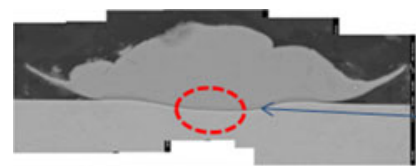

Analyzed region
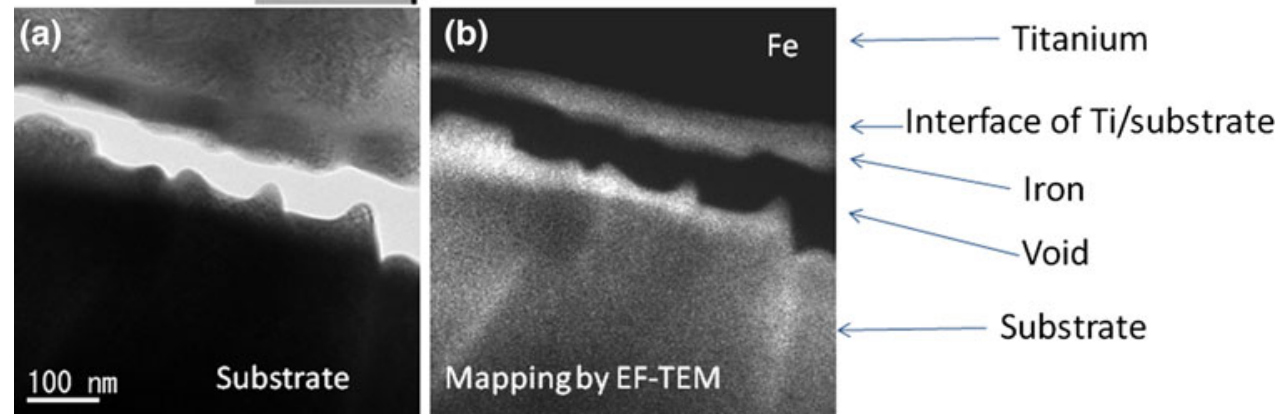

Fig. 22 TEM (a) and EFTEM images (b) of iron taken near the bottom of a titanium splat
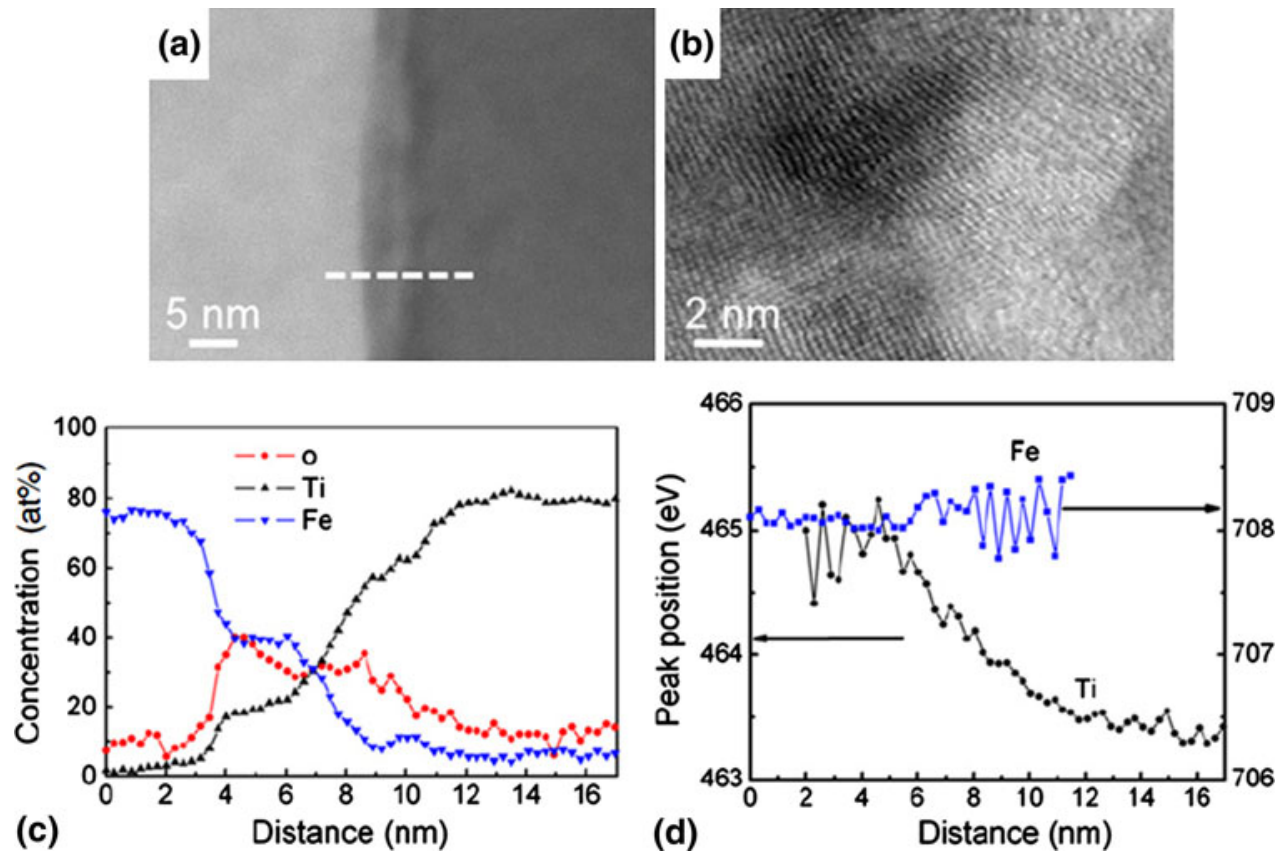

Fig. 23 STEM images and EELS analysis near the steel/titanium interface: (a) image of the boxed area of Fig. 4(a); (b) magnified view of panel (a) suggesting the presence of $\left(\begin{array}{lll}1 & 0 & 0\end{array}\right)$ oriented bcc steel in the left part and a partly disordered interface (right part); (c) and (d) analyses of an EELS line profile along the dotted line in (a) summarized (Ref 54)

deformation due to the adiabatic shear instability ejects surface oxide film to mate the fresh surfaces of the particle with the substrate to form bonding in the well-bonded region (Ref 8, 9, 11). Figure 22 shows an elemental mapping image of the south-pole region of a titanium splat obtained by the energy-filtered TEM technique (Ref 7-9, 54). A thin void was left at the bottom of the splat but very interestingly a thin layer of iron was attached to the bottom surface of the titanium particle. A possible interpretation of this is that a bond between the titanium particle and steel was formed temporarily by the compression during the impact but in the later stage when the interface was exposed to a high tensile stress due to the rebounding by the elastic energy accumulated during impacting, the bond was destroyed and a thin layer of the steel was exfoliated.

Highly magnified TEM images of the well-bonded interface region are shown in Fig. 23(a) and (b), indicating the existence of a layer of a few nm thickness with nanosize crystalline structure $(\operatorname{Ref} 8,12,54)$. Line profile by electron energy loss spectroscopy (EELS) in Fig. 23(c) shows that the thin layer contains significant concentration of oxygen as well as both $\mathrm{Ti}$ and Fe. The peak position in the energy spectra obtained from this region are shown in Fig. 23(d) which indicates that $\mathrm{Fe}$ is in metallic state, whereas $\mathrm{Ti}$ is in the oxidized state in the interface region corresponding to the distance from 2 to $6 \mathrm{~nm}$ and becomes metallic toward the inside as the oxygen concentration 

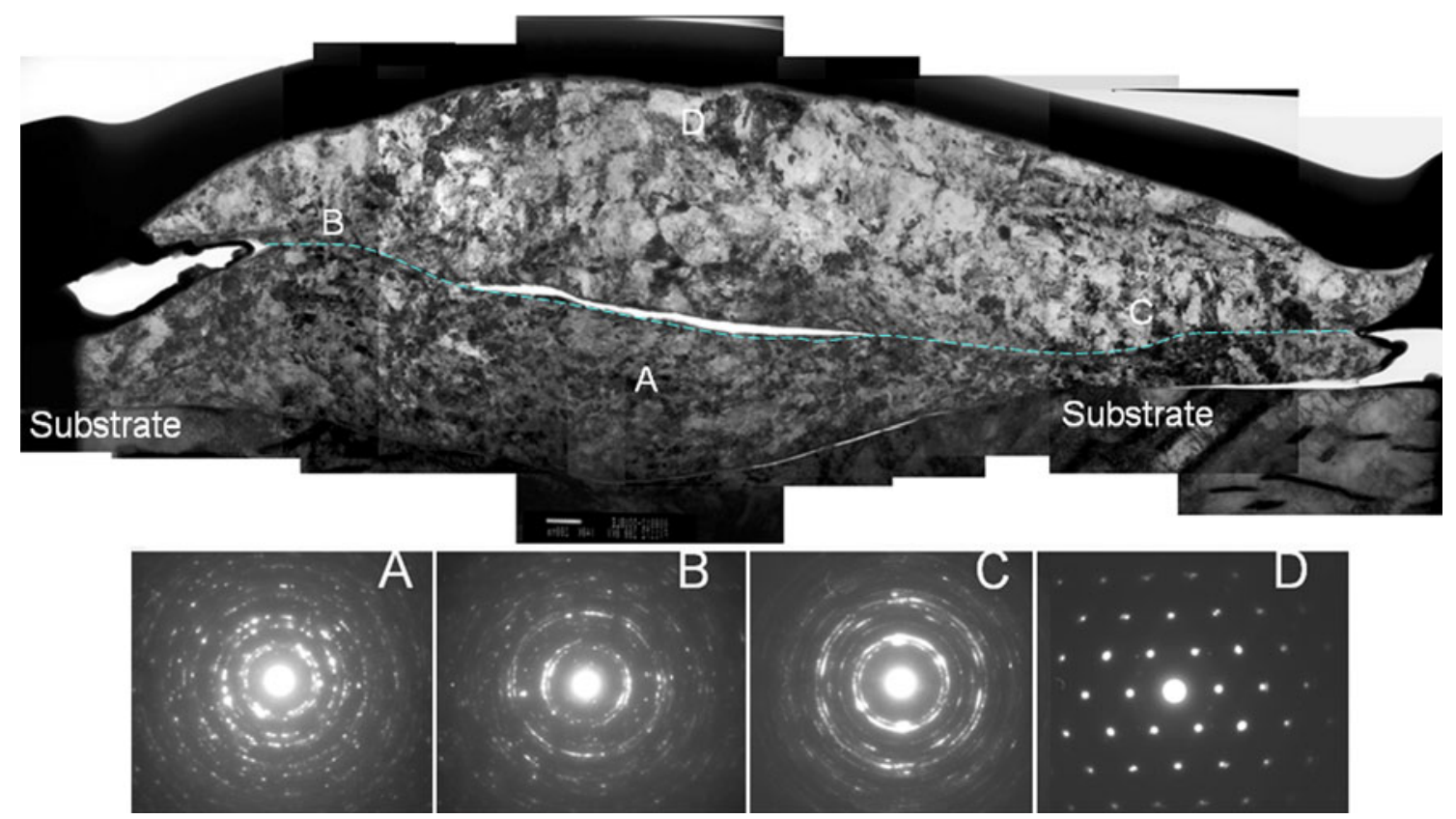

Fig. 24 TEM cross-sectional observation of two titanium particles impacted in a concentric configuration on a steel substrate (upper) and diffraction patterns obtained from selected regions (lower) (Ref 12)

decreases gradually. This is reasonable considering the large solubility of Ti up to about 15 mass\%. Therefore, the results indicate that there exists a thin interlayer in the well-bonded interface, which composed of mixture of nano-crystals of titanium oxide and metallic iron.

Since a coating is formed by numerous number of particles, effects of successive deposition of particles were examined (Ref 12). The first example shown in Fig. 24 represents a case of normal impact by the next particle which impacted almost concentrically to the first particle. It can be seen from the TEM image that (1) the upper region of the first particle was grain refined by the second impact, (2) the gap under the first particle at the southpole region is significantly closed. The four diffraction patterns from the regions marked as A, B, C, and D indicate that the first three regions have undergone severe plastic deformation accompanied with dynamic recrystallization, while the region $\mathrm{D}$ retains the microstructure of the feedstock powder. This is because the diffraction pattern $\mathrm{D}$ is a diffraction from a single crystal whereas the patterns $\mathrm{A}$ to $\mathrm{C}$ contain diffractions from multiple crystals, which means that the crystal sizes in region $\mathrm{D}$ is much larger as compared to the size of the selected area aperture of about $0.5 \mu \mathrm{m}$ diameter whereas the crystals are smaller than the aperture size in regions $\mathrm{A}$ to $\mathrm{C}$.

An example of side-impact is shown in Fig. 25 (Ref 12), where particle $A$ on the left arrived after particle B and collided with it from the side. It can be seen that some kind of weak bonding is formed but it is expected that such bonding is not very strong. In a real coating, interfaces with different natures are interwoven: strong interface made by high-velocity impact (shear instability), south-pole region bonded by successive impacts, and interface made by side-impacts. How these interfaces behave under various loading modes and affect transfer properties need to be studied.

\subsection{Metal Coatings}

Figure 26 exhibits the stress-strain curves of titanium coatings deposited by warm spraying with various nitrogen flow rates of $0.5,1.0,1.5,2.0 \mathrm{~m}^{3} / \mathrm{min}$ (Ref 55). Those data were obtained by tubular coating tensile (TCT) tests. The details of the test method can be found in the Ref 56, 57. The highest tensile strength of $250 \mathrm{MPa}$ and the largest elongation to failure $2 \%$ were obtained for the coatings deposited with the nitrogen flow rate of $1.0 \mathrm{~m}^{3} / \mathrm{min}$, which also had the lowest porosity as shown in Fig. 15. For either the lower or higher nitrogen flow rate, both tensile strength and elongation to failure were decreased significantly. In Fig. 27, SEM images of fracture surfaces after TCT tests were presented (Ref 55, 58). For the cases of nitrogen flow rate of 1.5 and $2.0 \mathrm{~m}^{3} / \mathrm{min}$, the spherical morphologies of original feedstock powder were still maintained after impact due to high deformation resistance. Failure mainly occurred at the interfaces among the particles implying lower bonding strengths. For the nitrogen flow rate of $1.0 \mathrm{~m}^{3} / \mathrm{min}$, particles were flattened more and the coating became denser because of higher temperatures and thermal softening of impacting particles. On the fracture surface, dimple formation from ductile fracture can be observed (Fig. 27d). However, the area is about $30 \%$ in the picture and the rest of it still shows the brittle failure. Thus, there is still room to improve the mechanical properties of the coating. For further reduction of nitrogen flow rate to $0.5 \mathrm{~m}^{3} / \mathrm{min}$, again the fracture surface became that of brittle nature. The detail analysis revealed the formation of oxides on the surface. Although 

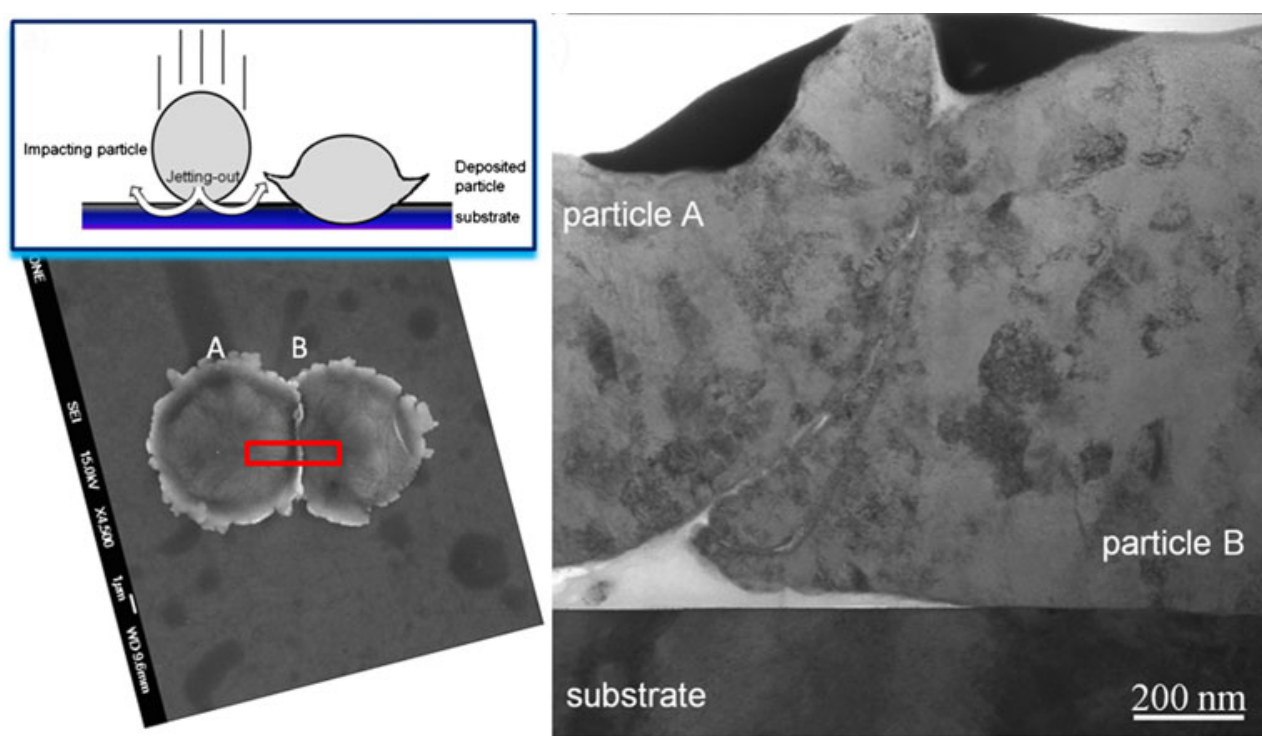

Fig. 25 SEM top view and TEM cross-sectional observation of two titanium particles impacted side by side on a steel substrate (Ref 12)

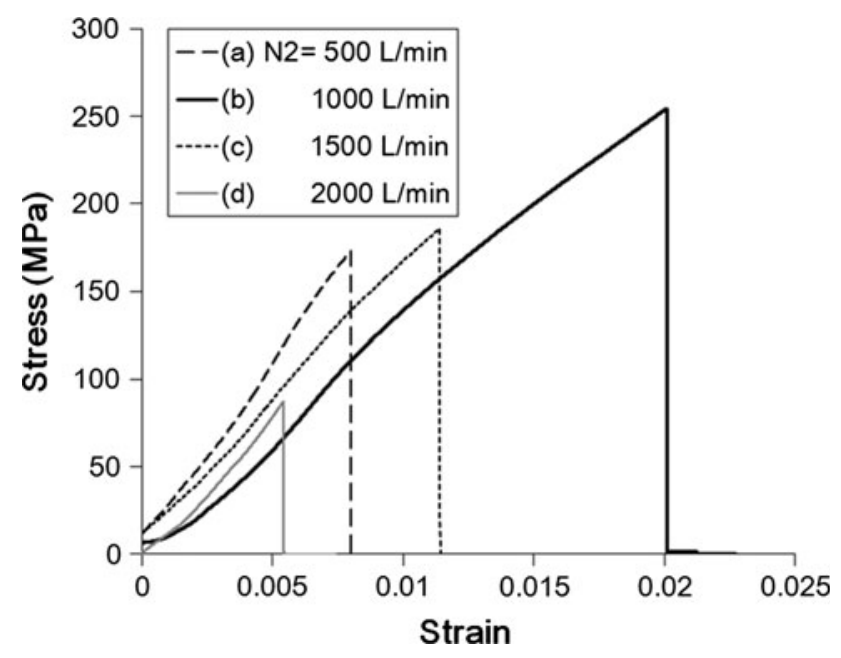

Fig. 26 Stress-strain curves in TCT tests of freestanding titanium coatings (Ref 55)

larger deformation of particles could be induced on impacts, as the thickness of the oxide layers on particles become thicker, it becomes more difficult to remove those oxides during impact and to form metal-metal bonding as elaborated in the previous sections, and the bonding comes to occur between amorphous titanium oxides (Ref 13). The results of the TCT tests clearly indicated that the existence of such interfacial oxides significantly decreases the strengths of coatings. The spray conditions used to fabricate the TCT samples were exactly the same with the ones in Fig. 18. In fact, the differences in the estimated velocities for the different nitrogen flow rates are within about $50 \mathrm{~m} / \mathrm{s}$ and the ones in the temperatures are only about $200 \mathrm{~K}$. Nevertheless, it is evident that the mechanical strengths of WS titanium coatings are significantly affected by such small differences, especially particle temperature.
The ultimate tensile strength of a pure bulk titanium for industrial use $(\mathrm{O}<0.2 \mathrm{wt} \%, \mathrm{~N}<0.05 \mathrm{wt} \%)$ is $350-530 \mathrm{MPa}$ and the elongation to failure is more than $23 \%$. There are large gaps compared to the TCT test results. One reason for the gap is the effect of test method. In TCT test, two cylindrical substrates are contacted but are not adhered to each other and thus these unbonded faces act like a crack and causes stress concentration near the tip area (Ref 57). Thus, the values obtained by TCT tests are usually 0.4-0.7 times as small as the ones of tensile test of free-standing coatings (Ref 55, 59). By taking account of this notch effect, the titanium coatings for $\mathrm{N}_{2}=1.0 \mathrm{~m}^{3} / \mathrm{min}$ appears to have similar strength with bulk counterparts, however, the elongation to failure is onetenth. Probably this poor plastic deformation is attributed to the existence of unbonded regions at the interfaces between particles as shown in Fig. 24. In addition, nonuniform nano/micrograin structures induced by local work hardening and grain refinements (Fig. 20, 24) can be other possible factors for such poor plastic deformation.

In Fig. 28, the tensile strength of $\mathrm{Ti}, \mathrm{Al}$, and $\mathrm{Cu}$ coatings obtained from TCT tests were indicated as a function of the nitrogen flow rate (Ref 55,58$)$. The tests were performed three times at least in all conditions. It reveals that the copper coatings show the highest strengths of about $450 \mathrm{MPa}$ for $1.5 \mathrm{~m}^{3} / \mathrm{min}$ throughout all nitrogen flow rates. The ultimate strength values increase constantly with the increase of $\mathrm{N}_{2}$ flow rate until $1.5 \mathrm{~m}^{3} / \mathrm{min}$ due to lower oxidation of copper particles. However, after the peak it drastically dropped to the lowest values at the $2.0 \mathrm{~m}^{3} / \mathrm{min}$ condition due to limited deformation of particles with lower particle temperature. Just like the titanium case, the nitrogen flow rate and thus particle temperature has a severe influence on the coating properties. In Fig. 28, the tensile strength of WS aluminum coatings is also plotted. It exhibited the highest value at $0.5 \mathrm{~m}^{3} / \mathrm{min}$ nitrogen flow rate and it monotonically 
decreased as the increase of $\mathrm{N}_{2}$ flow rate. Perhaps aluminum oxide is very stable and thus the variation of oxidation degree was very small. In such case, higher particle temperature can provide better bonding because of larger deformation on impact and thermally activated particle surfaces. In all three metals, the worst strength values were observed at the coldest condition (nitrogen flow rate of $2.0 \mathrm{~m}^{3} / \mathrm{min}$ ). These results ensure that the mechanical strengths of WS coatings strongly depend on particle deformability and oxidation.

Figure 29 is the comparison of the TCT test results with tensile strength of various copper coatings obtained by microflat tensile tests (Ref 55, 59). The highest tensile strength and elongation to failure obtained by WS coatings are comparable to cold-rolled bulk and CS coatings with helium gas. Since the titanium coating by cold spraying with helium gas is as dense as WS (Fig. 15) and copper is much softer than titanium, CS copper coatings with helium gas could be as dense as WS coatings. In addition, the bonding between particles could be similar or better with less oxidation in CS. Gaertner et al. (Ref 59) reported brittleness of as-sprayed CS copper coatings and the significant effects of heat treatments on them. The elongation to failure was significantly improved with the proper heating conditions due to enhanced interfacial bondings and recovering of work hardening. As already mentioned above, severe work hardening due to high speed impact make a coating harder and more brittle. In WS, the predeposited coating layers can be heated up by combustion flame and thus it can be moderately annealed during deposition simultaneously. It could be one possible explanation of better properties of WS copper coatings. More detailed research would lead further improvements of as-sprayed WS coatings.
$\mathrm{N} 2=500 \mathrm{~L} / \mathrm{min}$
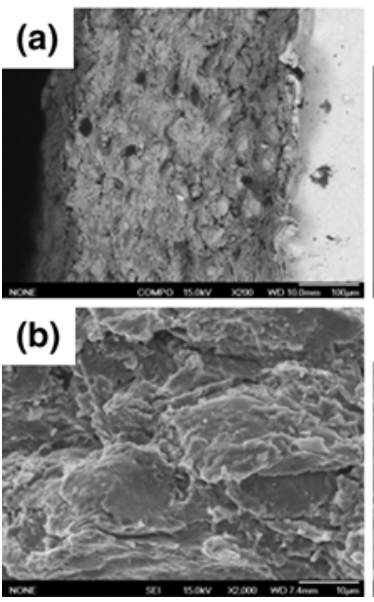

$\mathrm{N} 2=1000 \mathrm{~L} / \mathrm{min}$

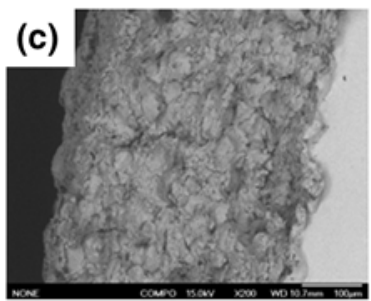

(d)

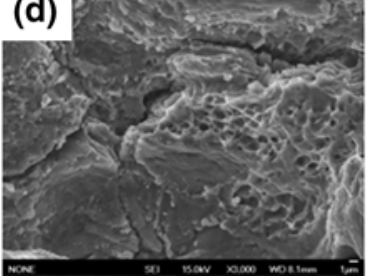

$\mathrm{N} 2=1500 \mathrm{~L} / \mathrm{min}$
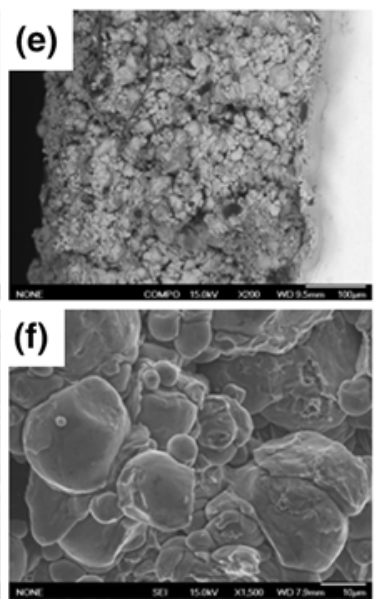

$\mathrm{N} 2=2000 \mathrm{~L} / \mathrm{min}$
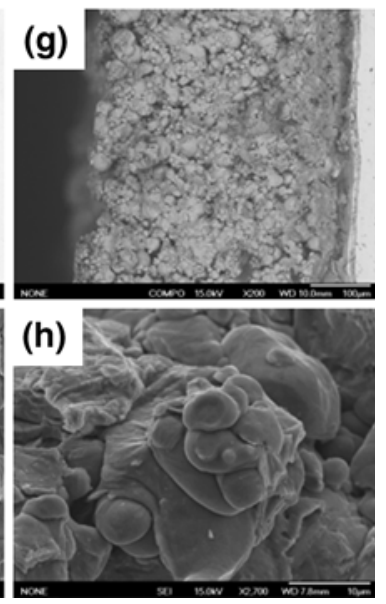

Fig. 27 Fracture surface of titanium coatings after TCT tests (Ref 55)

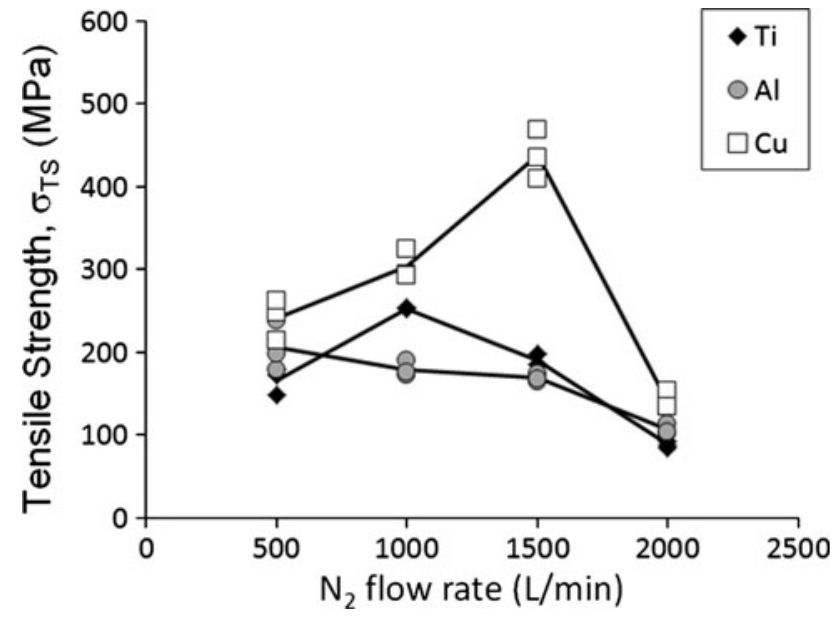

Fig. 28 Ultimate tensile strength in TCT tests of WS coatings as a function of $\mathrm{N}_{2}$ flow rate (Ref 55,58 )

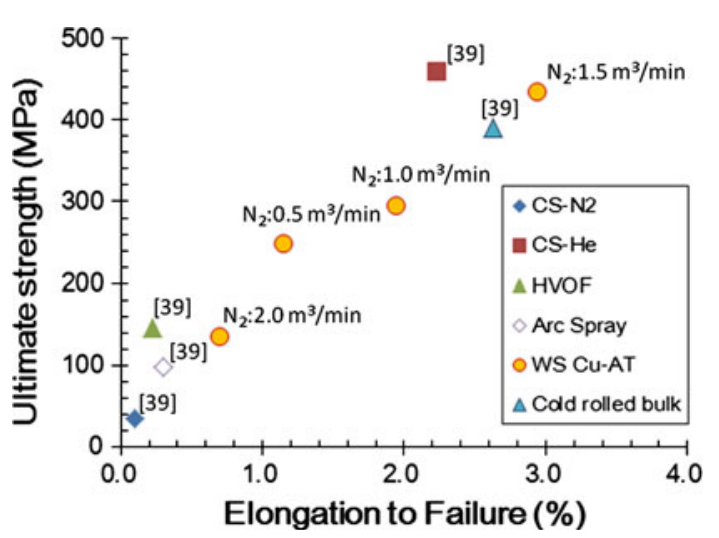

Fig. 29 Comparison of the tensile strength and elongation to failure in TCT test with the reference data of various copper coatings obtained by micro flat tensile test $(\operatorname{Ref} 55,59)$ 


\section{WC-Co Cermet Coatings}

\subsection{Coating Microstructure}

WC-Co cermet coatings have been used to the enhance wear resistance of various engineering components due to their high hardness and moderate toughness compared with other coating materials. HVOF spraying is known as the most suitable technique to fabricate WC-Co coatings so far, however, when compared to sintered WC-Co, which has been fabricated in carefully controlled sintering condition, HVOF-sprayed WC-Co coatings still suffer from decomposition and decarburization during spraying process, leading to a formation of undesirable phases such as $\mathrm{W}_{2} \mathrm{C}, \mathrm{W}$, and amorphous or nanocrystalline Co-W-C phase (Ref 60). By applying warm spray to deposit WC-Co, it is expected to suppress such detrimental reactions and to develop cermet coatings which consist of the similar microstructure and mechanical properties of sintered bulk materials.

Figure 30 contains the splat microstructures of WC12 wt. \% Co on carbon steel substrates and the examples of the splat cross sections of HVOF (Fig. 30a and c) and WS (Fig. 30b and d), respectively (Ref 15, 61). While the splat deposited by HVOF indicates melting and solidification on impacts, the one by WS kept the spherical shape of original feedstock powder indicating solid particle impact due to lower particle temperature. In the cross-sectional image of WS splat, the deeper impingement into the substrate and spherical morphology of the upper periphery of it can be understood. Since carbides are dissolved into Co binder in HVOF, the size of carbides in HVOF becomes smaller than the WS case.

The effects of nitrogen flow rate in WS on splat microstructures can be found in Fig. 31 (Ref 5, 15). Both splats kept spherical shape, but the carbide morphologies are different. When the particle temperature is relatively lower for the nitrogen flow rate of $1500 \mathrm{~L} / \mathrm{min}$, the carbides kept blocky shape, however, they were covered with locally melted binder phases for higher particle temperature in the nitrogen flow rate of $0.5 \mathrm{~m}^{3} / \mathrm{min}$. Example of the cross-sectional image of a WC- 12 wt.\%Co coating deposited by WS are presented in Fig. 32 (Ref 5, 15). Dense and thick coating enough for various applications can be obtained.

Figure 33 contains higher magnification images of HVOF and WS coatings (Ref 19). Both revealed a dispersion of fine carbide particles in binder phases. Pores were observed in both coatings. In some area of the HVOF WC-12Co coatings, lack of splat-splat bonding was also observed as shown in Fig. 33(a). A clear difference can be recognized in the coatings with higher Co content. In the HVOF coating of WC-25Co (Fig. 33c), the carbides are distributing in binder layers with different contrasts. These bright and dark binder layers were W-rich and Co-rich regions, respectively. The bright binder layer was not observed in the WS WC-25Co coating (Fig. 33d). Moreover, the carbide fractions in HVOF coatings were much lower than those in WS coatings. The shape of carbides in HVOF coating became rounder than that of WS coatings. The loss of carbide and change of carbide
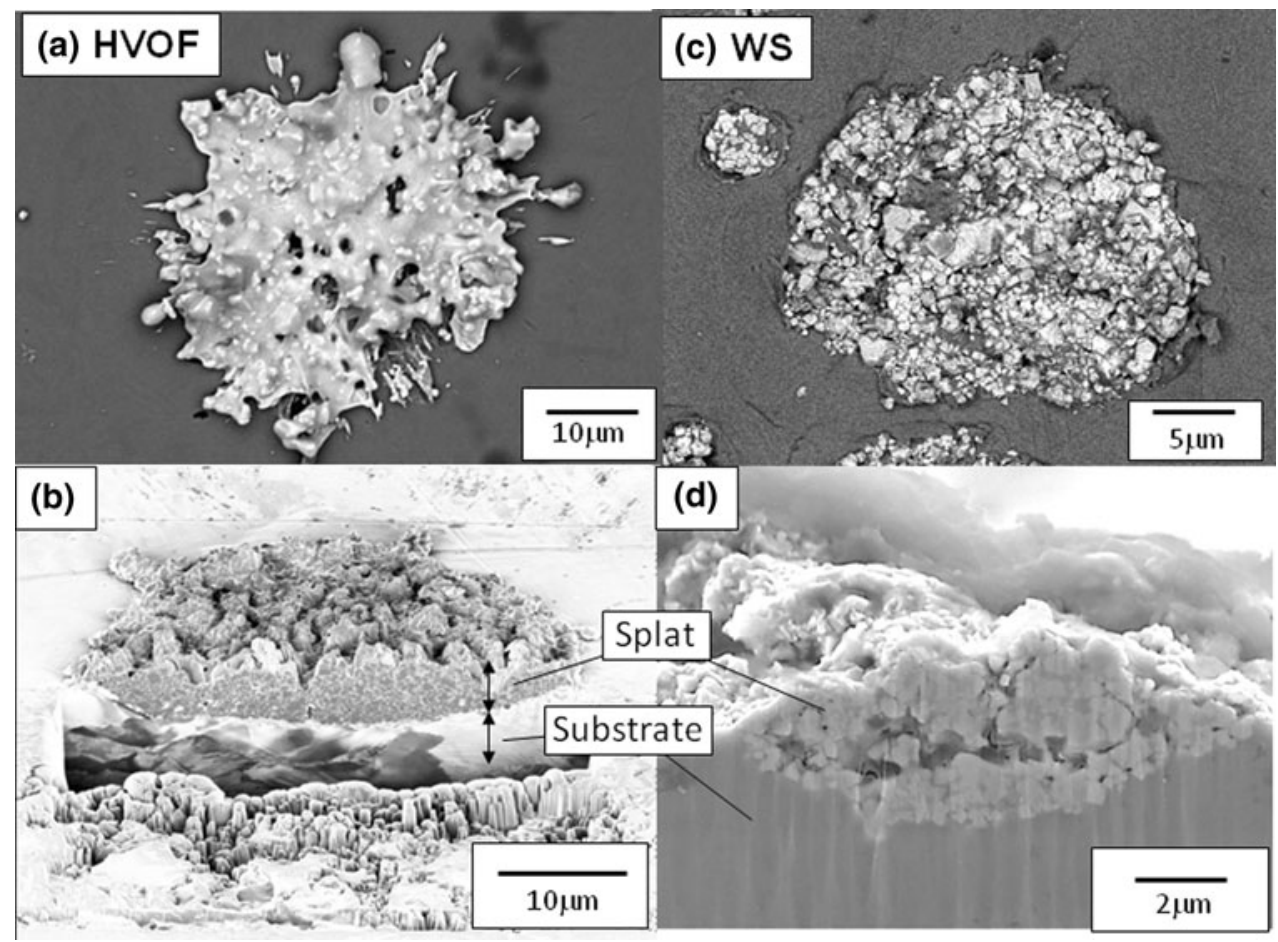

Fig. 30 Comparison of splat microstructures of WC-12Co in (a, c) HVOF and (b, d) WS (Ref 61). (c) and (d) are the cross-sectional images made by focused ion beam and cross section polisher, respectively 

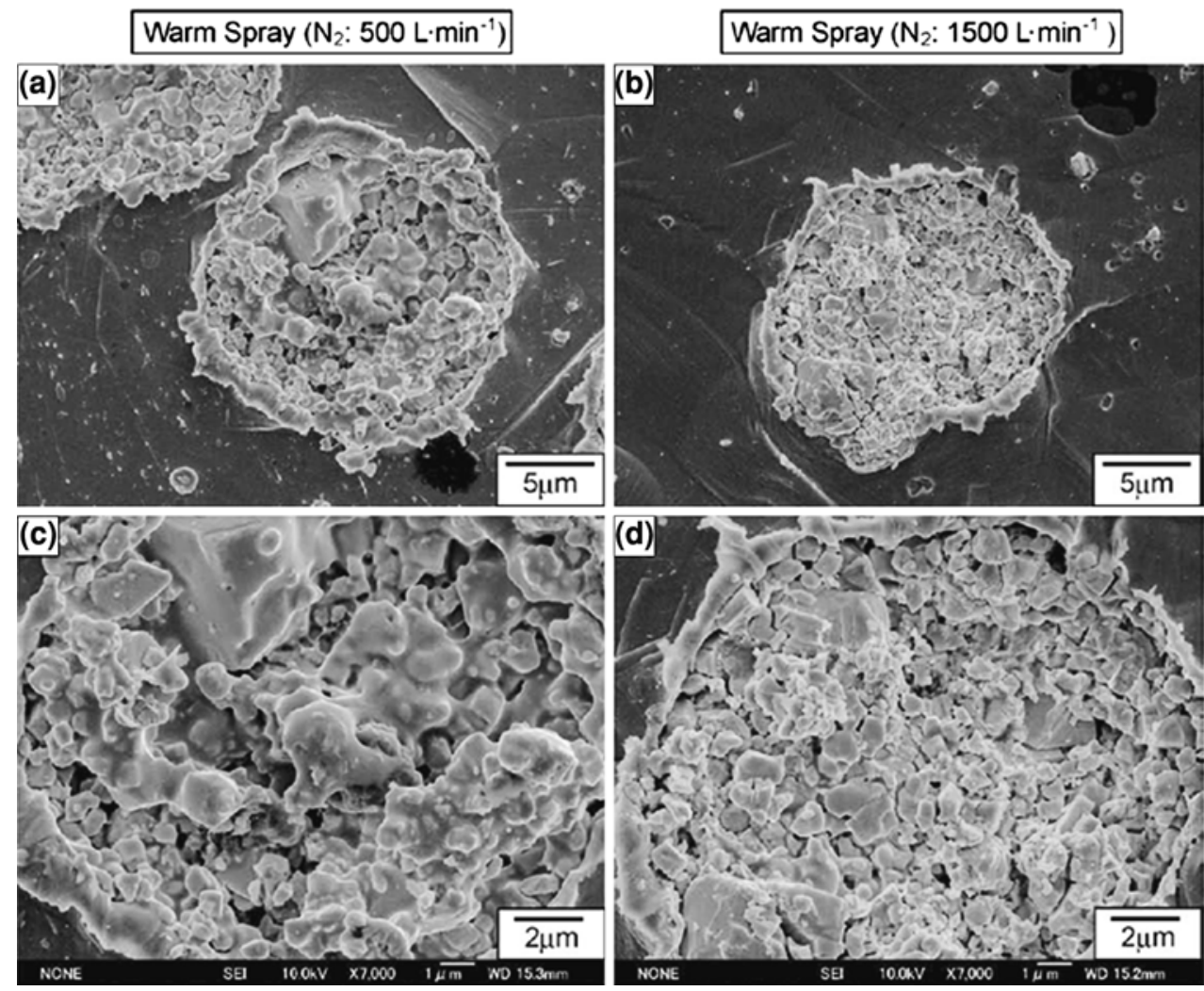

Fig. 31 Splat microstructures deposited by (a) HVOF, (b, d) warm spray with nitrogen flow rate of $500 \mathrm{~L} / \mathrm{min}$, and (c, e) warm spray with nitrogen $1500 \mathrm{~L} / \mathrm{min}$. (d, e) are higher magnification images of (b) and (c), respectively (Ref 15)

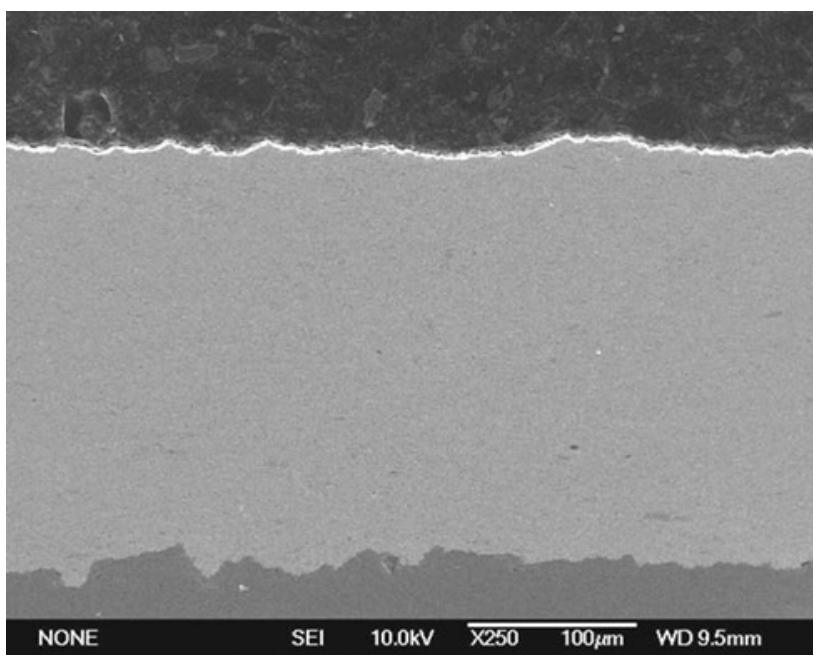

Fig. 32 Cross-sectional image of a coating deposited by warm spray deposition (Ref 15)

morphology in HVOF coatings could be attributed to the dissolution of WC into the Co binder, while such reaction can be suppressed by WS process. This process provides a deposition of feedstock powder in solid state, therefore the microstructure of the coating results from the stacking of particles under impact.
Examples of XRD patterns of HVOF and WS coatings are shown in Fig. 34(a) and (b), respectively (Ref 19). The results of WC-12Co feedstock powder is also given for a comparison. While the original powder contained only the peaks of Co and WC, HVOF coatings showed the crystalline peaks of $\mathrm{WC}, \mathrm{W}_{2} \mathrm{C}, \mathrm{W}$ and a broad shoulder at the angle of the Co peak, indicating that the binder has become amorphous or nanocrystalline form. There is a tendency for amorphous peak to increase as the Co content increases, while $\mathrm{W}_{2} \mathrm{C}$ tended to decrease. In the case of WS coatings, only the peaks of WC and Co phase can be recognized for the 17 and $25 \%$ Co contents, while a very small peak of $\mathrm{W}_{2} \mathrm{C}$ is observed in the $12 \%$ Co content. This meant that WS process can significantly suppress the decomposition and oxidation during deposition. The Co peaks of WS coatings were broadened and shifted to lower angles (Fig. 34b). One possible explanation of this substantial peak shift can be high residual compressive stress in the binder due to large deformation of soft Co binder and constraining by the surrounding carbides. Another explanation could be the formation of high pressure phase of Co due to high speed impact, but this remains as a subject of further investigation. For broadening of the peak, since the high speed impact of solid particle induces the dynamic recrystallization and leads to the formation of nanoorder polycrystalline structure as can be seen in titanium splat (Fig. 20), the formation of such nanocrystalline microstructure can be the reason for the broadening. 

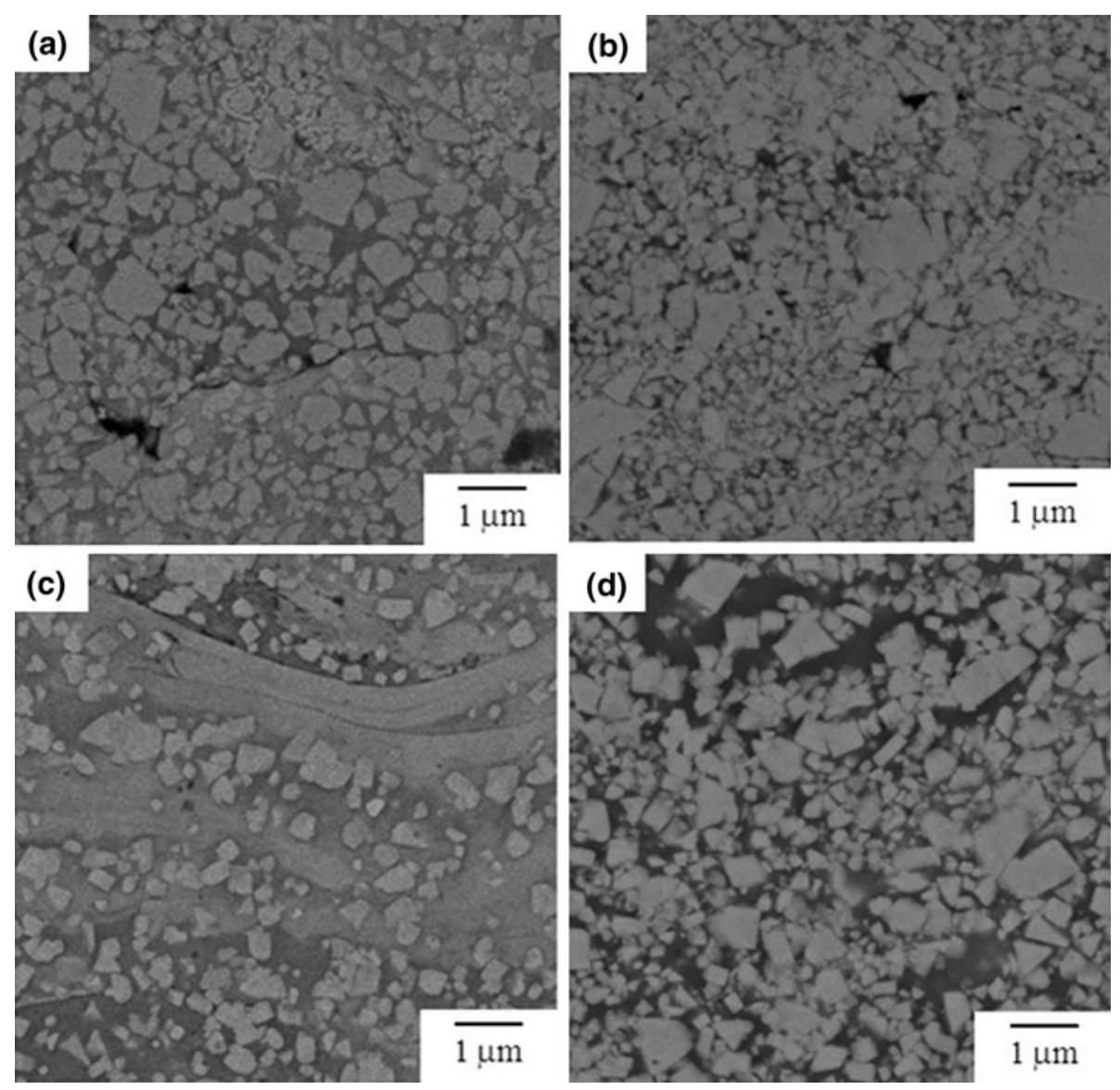

Fig. 33 SEM observations of (a) HVOF WC-12Co, (b) WS WC-12Co, (c) HVOF WC-25Co, and (d) WS WC-25Co coatings (Ref 20)

\subsection{Mechanical Properties of the Coating}

5.2.1 Hardness and Fracture Resistance. The Vickers hardness (load $0.3 \mathrm{kgf}$ ) and fracture resistance values of the HVOF and WS coatings as a function of Co content are shown in Fig. 35 (Ref 19, 20). Two types of feedstock powder F-series and $\mathrm{C}$-series with different powder size were used for WS sample preparations in order to investigate the effect of particle size. For HVOF, only C-series powder was used because of the spitting problem of F-series powder. The powder $\mathrm{F}$ contained finer particles of 5-20 $\mu \mathrm{m}$ and the powder $\mathrm{C}$ had the coarser particles of 15-45 $\mu \mathrm{m}$ (Fig. 36) (Ref 20). The fracture resistance were evaluated by indentation fracture (IF) method (Ref 19). It should be noted that the precision of the fracture toughness obtained by the IF method for such thin coatings are arguable but it is still a very useful parameter for the quantitative comparison. Due to this, it is called as fracture resistance $K_{\mathrm{c}}$ in this article. The values of the sintered materials are also given for a comparison. The WS coatings had lower hardness values than those of the sintered ones for all the Co contents, however, a trend of hardness reduction with Co content was the same. In contrast, the hardness of HVOF coatings only slightly changed with Co content. These are related to the different phase distribution between WS and HVOF coatings as elaborated above (Ref 19). F-series coatings showed higher hardness values than C-series coating by about $100 \mathrm{Hv}$ for all the Co contents. SEM observations and mercury porosimetry of the coatings revealed the lower porosity in F-series coatings than C-series, which implies the better splat-splat bonding by using finer feedstock powder in WS WC-Co coatings (Ref 20).

The fracture resistance of WS coatings showed a tendency to increase with increasing Co contents, however, the increment was not as large as that of sintered WC-Co. The fracture resistance of both $\mathrm{C}$ - and F-series coatings ranged from 4 to $6 \mathrm{MPam}^{1 / 2}$. In HVOF, the fracture resistance reduced as Co content increases probably due to embrittlement of binder phases. As mentioned above, reducing powder size lowered defects and enhanced splatsplat bonding in the WS coating leading to the increase of hardness, however, no improvement was recognized in terms of fracture resistance. Figure 37 shows the crosssectional images of the crack configurations in WC-17Co coatings deposited by (a) HVOF and (b) WS, respectively. The drastic reduction in crack length can be recognized in WS sample indicating the effectiveness of suppression of the formation of brittle phases such as $\mathrm{W}_{2} \mathrm{C}$ and amorphous binder phases. These values, however, are still lower than those of bulk WC-Co (9-14 MPam $\left.{ }^{1 / 2}\right)$. The 

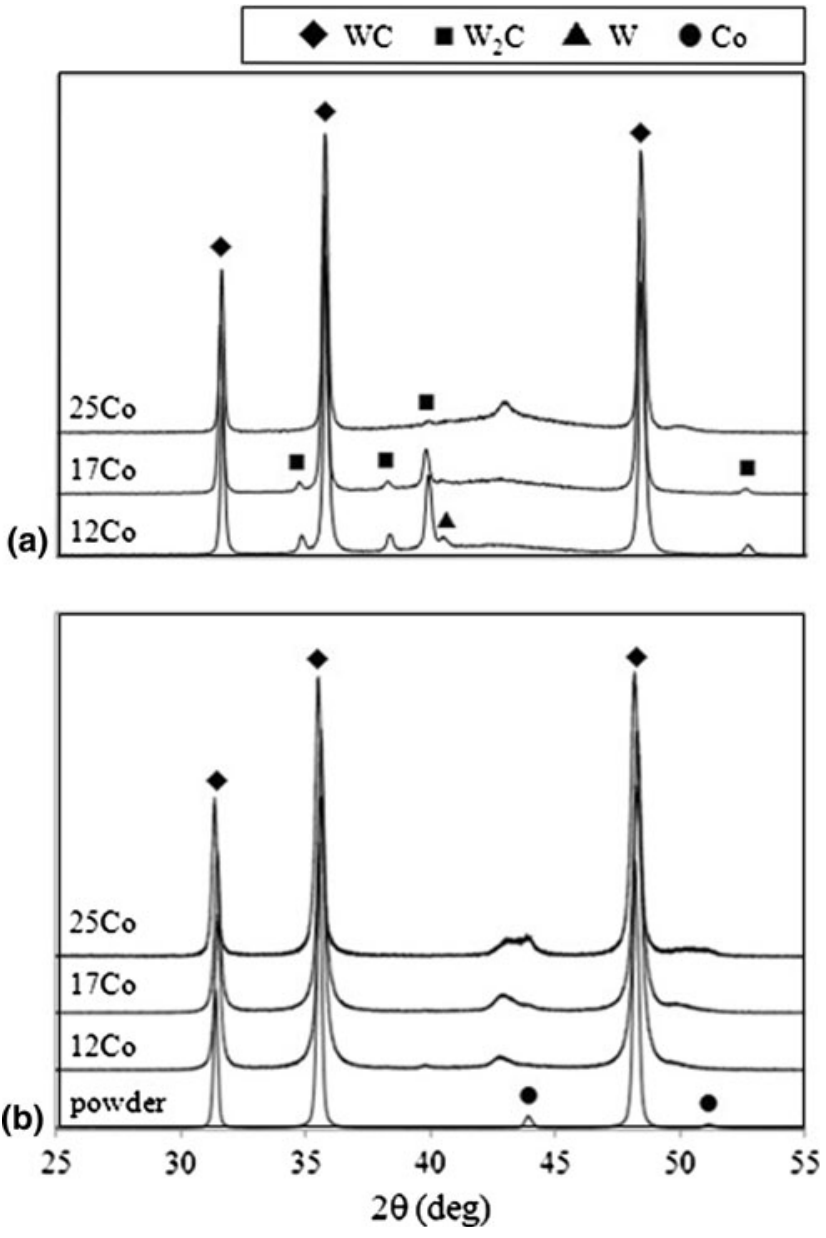

Fig. 34 XRD results of (a) HVOF and (b) WS coatings. The result of WC-12Co powder coatings is given for a comparison (Ref 20)

reason of the large gap may be caused by the existence of the microstructural defects such as pores, which can be recognized in Fig. 38 (Ref 62). Although the bonding mechanism of a WC-Co particle in WS deposition is yet to be studied, it is hypothesized that Co binder would work as a kind of glue with significant deformation on impact. Thus, if there were not enough amounts of Co on the surface of a particle locally, for example, due to nonuniform distribution of $\mathrm{Co}$ in one particle, those regions could be poorly bonded. More detail experiments are required to minimize the gap between a bulk material and a WS coating.

5.2.2 Surface Roughness. One very promising feature of WS WC-Co coating is the smoother coating surface in as-sprayed state, because it is possible to spray fine powder, which cannot be sprayed by conventional HVOF due to spitting problem, in which a deposit of excessively molten sprayed particles adhere and grow on the inside wall of a nozzle of the spray gun and is ejected as large and irregular droplets. In Fig. 39, the cross-sectional images around the surfaces of three WC-12Co coatings were presented, which were fabricated from the different feedstock powder consisting with different particle sizes
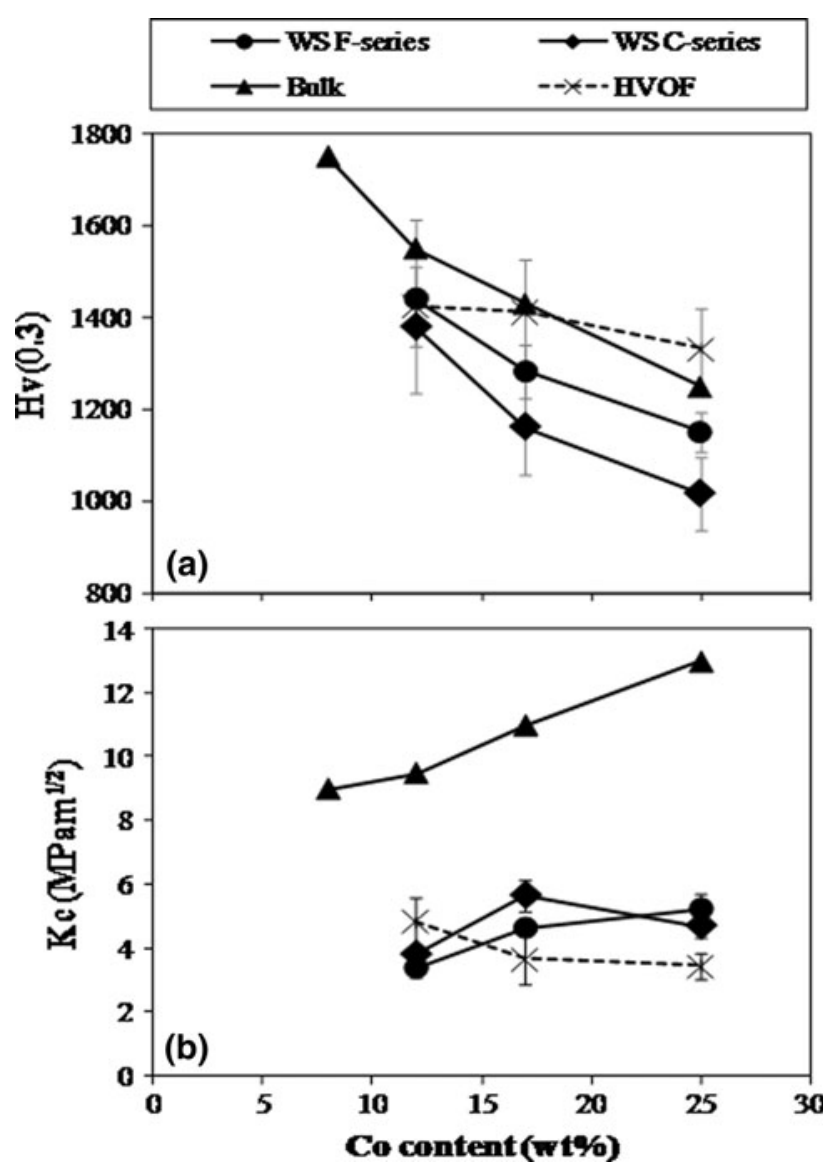

Fig. 35 (a) Hardness and (b) fracture resistance as a function of cobalt content. Values of the sintered materials were given for a comparison $(\operatorname{Ref} 19,20)$

$\left(D_{50}=28.5,15.9,7.5 \mu \mathrm{m}\right)(\operatorname{Ref} 63)$. As the powder size becomes finer, the surface roughness becomes smaller. The surface roughness of those three coatings, i.e., $R_{\mathrm{a}}$ values were evaluated by the profilometer with a small needle (Fig. 40) (Ref 63). $R_{\mathrm{a}}$ is defined as $R_{\mathrm{a}}=$ $(1 / l) \int_{0}^{l}\{f(x)\} d x$, where $f(x)$ is the surface profile at a position $x$ and $l$ is a sampled standard length. The surface roughness $R_{\mathrm{a}}$ of WS WC-12Co is $1.22,1.44$, and $5.56 \mu \mathrm{m}$ for the three powders. For coatings by conventional HVOF, the reported values of $R_{\mathrm{a}}$ are in the range of 3-6 $\mu \mathrm{m}$ (Ref 62-64). The smoother surface just after coating deposition can reduce costs and time for final polishing of commercial products. In addition, the achievable minimum surface smoothness could be much smaller in WS than HVOF due to suppression of degradation of binder phase and due to the possibility to avoid the spallation of carbides during polishing. The distribution of Vickers hardness and surface roughness of WS and HVOF WC-12Co coatings from F- and C-series powder were plotted for various spray conditions (Fig. 41) (Ref 62, 64). It should be noted that only one data point is plotted for HVOF WC-12Co from F-series powder because it is very difficult to obtain coatings due to spitting in this combination. Such condition cannot be used in the practical applications. It is very important that while the 

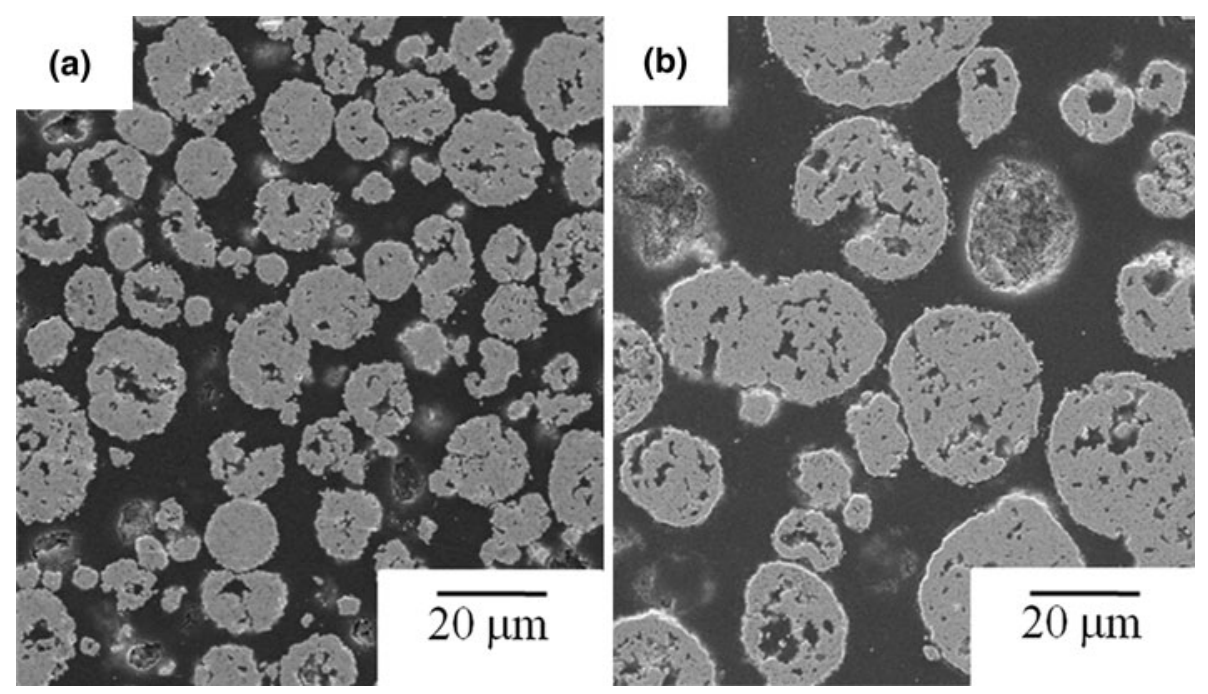

Fig. 36 SEM observation of cross section of WC-12Co powder: (a) $-20+5 \mu \mathrm{m}$ and (b) $-45+15 \mu \mathrm{m}(\operatorname{Ref} 20)$
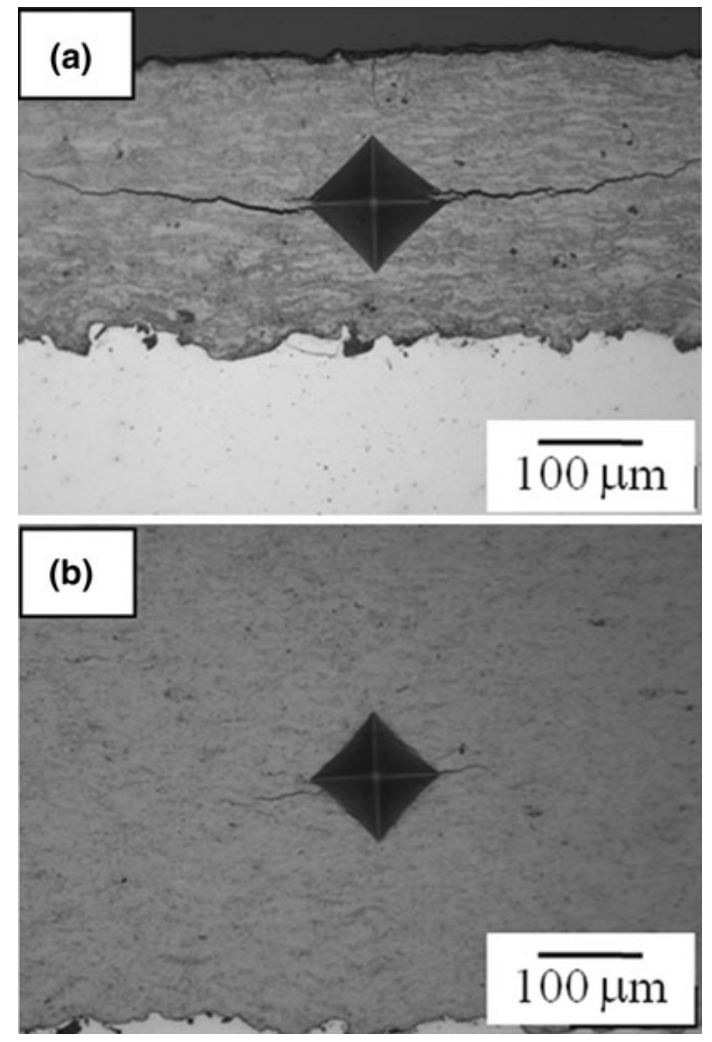

Fig. 37 Cracks generated by the indentation fracture toughness test (load: $10 \mathrm{kgf}$ ) in WC-12Co coatings by (a) HVOF and (b) WS deposition. Drastic reduction of crack length can be recognized in the WS coating (Ref 19)

conventional HVOF WC-12Co coatings have the hardness of $1100-1300 \mathrm{Hv}$ (for $0.3 \mathrm{kgf}$ load) and the surface roughness $\left(R_{\mathrm{a}}\right)$ of 3-4, WS WC-12Co can achieve much higher hardness $(1600 \mathrm{Hv})$ and much smoother surface roughness $\left(R_{\mathrm{a}}=1-2 \mu \mathrm{m}\right)$ simultaneously.

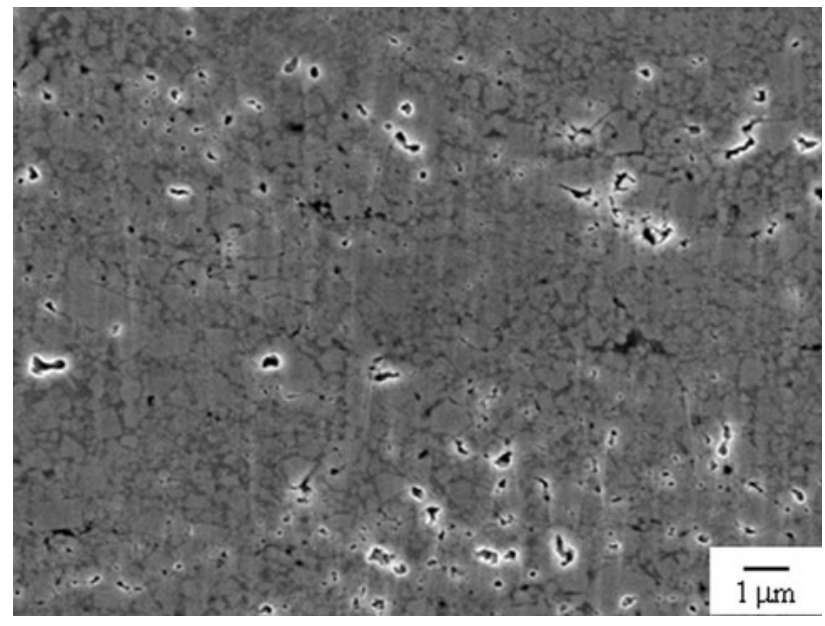

Fig. 38 Cross-sectional image of WC-12Co coating (WC size: $0.2 \mu \mathrm{m})$ prepared by cross section polisher (Ref 62)

5.2.3 Erosion Behavior. Erosion wear property of $\mathrm{C}$ - and F-series coatings as a function of Co contents is shown in Fig. 42 (Ref 20). The data are presented in terms of the volume wear ratio, which is the volume loss of a coating normalized by that of a low carbon steel (JIS-SS400). Solid and dashed lines represent the results obtained from impact angles of $30^{\circ}$ and $90^{\circ}$, respectively. It clearly shows that the volume losses at $90^{\circ}$ impact angle were higher than those at $30^{\circ}$ for all Co contents, which is a typical erosion characteristic of brittle materials. The coatings' performance was actually inferior to the carbon steel at $90^{\circ}$. The volume wear ratio tended to linearly increase with increasing Co content for both $30^{\circ}$ and $90^{\circ}$ impact angles and F-series coatings showed less volume loss than C-series coatings. Previous studies about erosion of thermal sprayed cermet coatings described the erosion mechanism as follows. The first stage of erosion is caused by microcutting and microploughing of the soft binder by 

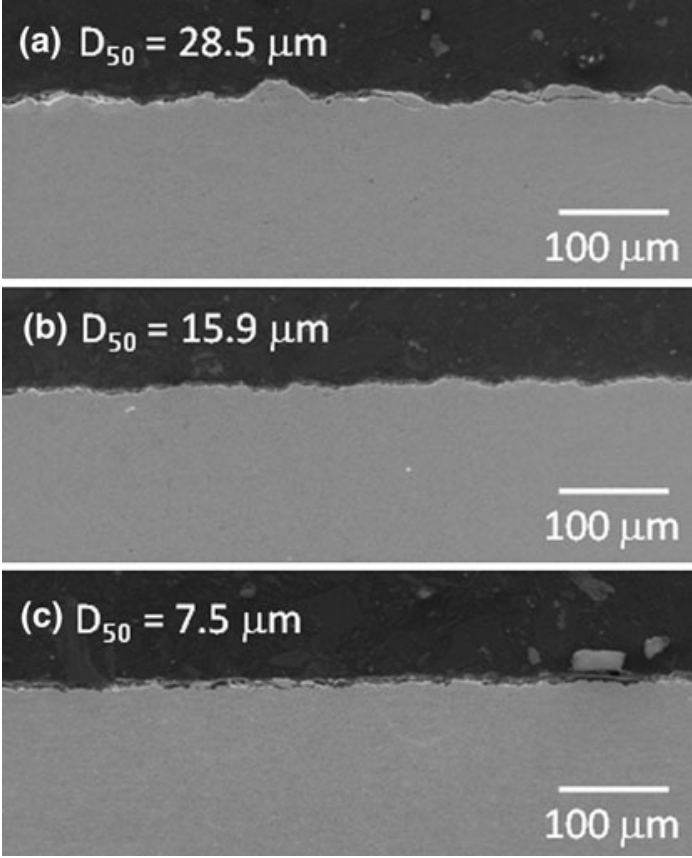

Fig. 39 Cross-sectional images around the surfaces of WS WC12 Co coatings from the different feedstock powder in terms of particle size distributions (Ref 63, 64)

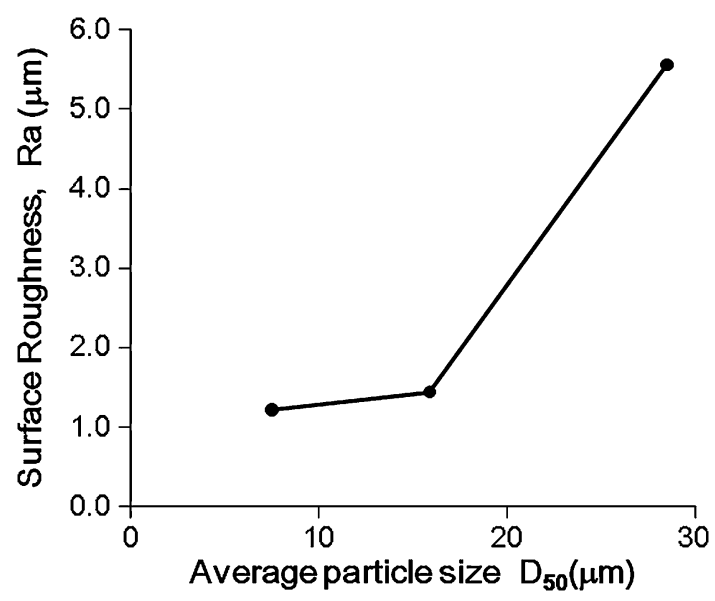

Fig. 40 Variation of surface roughness of WS WC-12Co coatings as a function of average particle sizes in feedstock powder (Ref 63, 64)

hard erodent particles. With progress of erosion, the carbide particles are exposed and then gouged by the impact of erodent particles and cause further cutting. The second is the spalling of the coating due to crack propagation. According to the observation of erosion wear morphology, the main erosion mechanism of the WS WC-Co coatings is also the latter one similar to conventional thermal spray coatings. The degree of spalling in the F-series coatings was considered to be lower than those in C-series coatings. The improvement in wear properties in F-series coating was attributed to the improvement of splat-splat bonding and reduction in porosity.

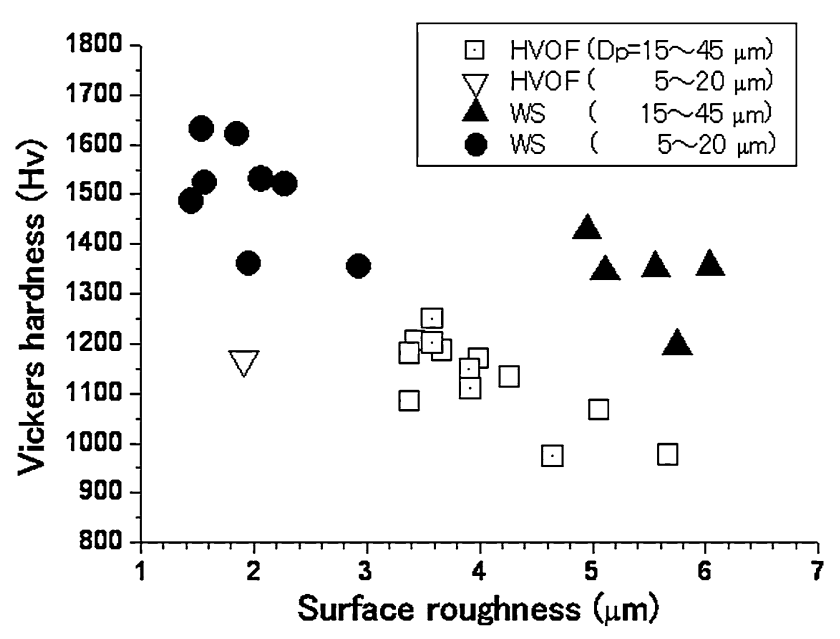

Fig. 41 Map of surface roughness and Vickers hardness of HVOF and WS WC-12Co coatings for different feedstock powder size (Ref 62, 64)

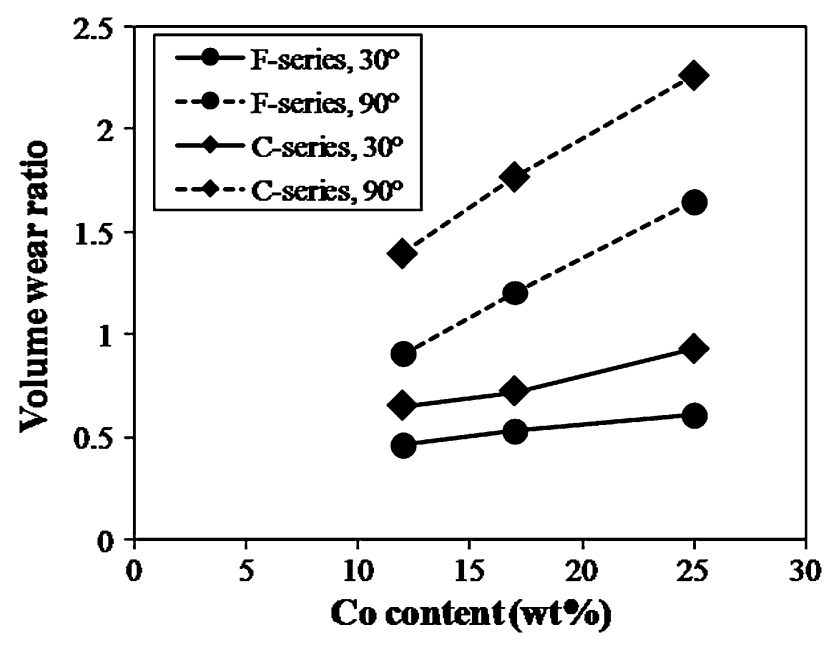

Fig. 42 Erosion wear rate as a function of cobalt content (Ref 20)

\section{Conclusion}

Warm spray process has been developed on the basis of an HVOF apparatus using combustion gas. This, however, is just one route to achieve the concept of warm spray, i.e., coating deposition by high-velocity impact of thermally softened solid powder particles. Process developments from different approaches are expected as the merits of warm spraying become better and more widely understood. In this review article, following points were presented to elucidate the characteristics of the warm spray process as well as some distinct characteristics of WS coatings to be explored for industrial applications in the near future:

(1) Warm spray was conceived in the efforts to improve the corrosion barrier capability of HVOF metallic coatings such as the density and degree of oxidation in 
the Ultra-Steel Project conducted in NIMS from 1997 to 2006. Its main feature is the ability of control the temperature of the propellant gas while keeping the high velocity of HVOF.

(2) Numerical simulation of the gas flow field and particle acceleration/heating of warm spray in comparison with HVAF revealed the higher degree of control over the powder temperature by the former process.

(3) Titanium coatings with various degrees of porosity and oxidation could be fabricated by warm spray, where the nitrogen flow rate controlling the gas temperature was the dominant process parameter. Low porosity below 1 vol. $\%$ with oxygen pickup below 0.25 mass \% were possible for the feedstock powder with $0.14 \%$ oxygen content.

(4) Process map analysis of warm spray clarified the merits of thermal softening as an effective means to lower the critical velocity to achieve bonding and realize dense coating structure by high deformability in the thermally softened state of the powder.

(5) High-resolution study of titanium splats by using TEM revealed the microstructure of various bonding interfaces created by warm spraying. They ranged from intimate metal-metal bonding, bonding via nm-scale oxide film, which can be crystalline or amorphous, and bonding formed by closure of the initially debonded south-pole regions by successive impacts of subsequent particles.

(6) Tensile mechanical properties of several metallic coatings revealed the characteristics of warm-sprayed coatings and how they are sensitive to the impacting state of powder particles, which determine the degree of inter-particle bonding and the thickness of oxides at the interfaces.

(7) Warm sprayed cermet coatings such as WC-Co are exhibiting certain advantages such as higher hardness, more homogeneous and fine microstructure, and fine surface quality, which should be cultivated for some advanced industrial applications.

\section{Acknowledgments}

We express our appreciation to Dr. J. Kawakita for his early contributions to HVOF coatings characterization and warm spray developments, Messrs. M. Komatsu and Hiraoka for skillful operation of spray equipment at the National Institute for Material Science. Dr. Y. Ishikawa (currently at Asahi Glass Co., Ltd.), Dr. P. Chivavibul (currently at the University of Tokyo) and Dr. G.S. Raman (currently at IIT Madras) are thanked for their sincere research concerning cermet coatings at NIMS. Dr. J. Kitamura and Mr. K. Sato of Fujimi Incorporated are thanked for their support and collaboration in conducting WS research on WC-Co cermet coatings. Dr. H. Fukanuma and Dr. R.Z. Huang of Plasma Giken Kogyo Co., Ltd. are thanked for providing us with cold-sprayed samples and the data of CS particles state at impact obtained by numerical simulation.

\section{References}

1. J. Kawakita, S. Kuroda, S. Krebs, and H. Katanoda, In situ Densification of Ti Coatings by the Warm Spray (Two-Stage HVOF) Process, Mater. Trans., 2006, 47(7), p 1631-1637

2. J. Kawakita, S. Kuroda, T. Fukushima, H. Katanoda, K. Matsuo, and H. Fukanuma, Dense Titanium Coatings by Modified HVOF Spraying, Surf. Coat. Technol., 2006, 201(3-4), p 1250-1255

3. K. Yokoyama, M. Watanabe, S. Kuroda, Y. Gotoh, T. Schmidt, and F. Gartner, Simulation of Solid Particle Impact Behavior for Spray Processes, Mater. Trans., 2006, 47(7), p 1697-1702

4. M. Watanabe, S. Kishimoto, Y. Xing, K. Shinoda, and S. Kuroda, Evaluation of Strain Field Around Impacted Particles by Applying Electron Moire Method, J. Therm. Spray Technol., 2007, 16(5-6), p 940-946

5. S. Kuroda, J. Kawakita, M. Watanabe, and H. Katanoda, Warm Spraying-A Novel Coating Process Based on High-Velocity Impact of Solid Particles, Sci. Technol. Adv. Mater., 2008, 9(3), p 033002

6. K. Kim, M. Watanabe, J. Kawakita, and S. Kuroda, Grain Refinement in a Single Titanium Powder Particle Impacted at High Velocity, Scr. Mater., 2008, 59(7), p 768-771

7. K. Kim, M. Watanabe, and S. Kuroda, Thermal Softening Effect on the Deposition Efficiency and Microstructure of Warm Sprayed Metallic Powder, Scr. Mater., 2009, 60(8), p 710-713

8. K. Kim, M. Watanabe, and S. Kuroda, Jetting-Out Phenomenon Associated With Bonding of Warm-Sprayed Titanium Particles onto Steel Substrate, J. Therm. Spray Technol., 2009, 18(4), p 490499

9. K. Kim, M. Watanabe, J. Kawakita, and S. Kuroda, Effects of Temperature of In-flight Particles on Bonding and Microstructure in Warm-Sprayed Titanium Deposits, J. Therm. Spray Technol., 2009, 18(3), p 392-400

10. H. Katanoda, T. Kiriaki, T. Tachibanaki, J. Kawakita, S. Kuroda, and M. Fukuhara, Mathematical Modeling and Experimental Validation of the Warm Spray (Two-Stage HVOF) Process, J. Therm. Spray Technol., 2009, 18(3), p 401-410

11. K. Kim, M. Watanabe, and S. Kuroda, Bonding Mechanisms of Thermally Softened Metallic Powder Particles and Substrates Impacted at High Velocity, Surf. Coat. Technol., 2010, 204(14), p 2175-2180

12. K. Kim, S. Kuroda, and M. Watanabe, Microstructural Development and Deposition Behavior of Titanium Powder Particles in Warm Spraying Process: From Single Splat to Coating, J. Therm. Spray Technol., 2010, 19(6), p 1244-1254

13. K. Kim and S. Kuroda, Amorphous Oxide Film Formed by Dynamic Oxidation During Kinetic Spraying of Titanium at High Temperature and Its Role in Subsequent Coating Formation, Scr. Mater., 2010, 63(2), p 215-218

14. H. Katanoda, H. Morita, M. Komatsu, and S. Kuroda, Experimental and Numerical Evaluation of the Performance of Supersonic Two-Stage High-Velocity Oxy-Fuel Thermal Spray (Warm Spray) Gun, J. Therm. Sci., 2011, 20(1), p 88-92

15. M. Watanabe, C. Pornthep, S. Kuroda, J. Kawakita, J. Kitamura, and K. Sato, Development of WC-Co Coatings by Warm Spray Deposition for Resource Savings of Tungsten, J. Jpn. Inst. Met., 2007, 71(10), p 853-859

16. J. Kawakita, T. Shinohara, S. Kuroda, M. Suzuki, and S. Sodeoka, Fabrication of Nano-Sized Oxide Composite Coatings and PhotoElectric Conversion/Electron Storage Characteristics, Surf. Coat. Technol., 2008, 202(16), p 4028-4035

17. J. Kawakita, N. Maruyama, S. Kuroda, S. Hiromoto, and A. Yamamoto, Fabrication and Mechanical Properties of Composite Structure by Warm Spraying of Zr-Base Metallic Glass, Mater. Trans., 2008, 49(2), p 317-323

18. J. Kawakita, H. Katanoda, M. Watanabe, K. Yokoyama, and S. Kuroda, Warm Spraying: An Improved Spray Process to Deposit Novel Coatings, Surf. Coat. Technol., 2008, 202(18), p 4369-4373

19. P. Chivavibul, M. Watanabe, S. Kuroda, J. Kawakita, M. Komatsu, K. Sato, and J. Kitamura, Development of WC-Co Coatings Deposited by Warm Spray Process, J. Therm. Spray Technol., 2008, 17(5-6), p 750-756

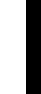


20. P. Chivavibul, M. Watanabe, S. Kuroda, J. Kawakita, M. Komatsu, K. Sato, and J. Kitamura, Effect of Powder Characteristics on Properties of Warm-Sprayed WC-Co Coatings, J. Therm. Spray Technol., 2010, 19(1-2), p 81-88

21. S. Sampath, X. Jiang, A. Kulkarni, J. Matejicek, D.L. Gilmore, and R.A. Neiser, Development of Process Maps for Plasma Spray: Case Study for Molybdenum, Mater. Sci. Eng. A Struct. Mater. Prop. Microstruct. Process., 2003, 348(1-2), p 54-66

22. A. Vaidya, T. Streibl, L. Li, S. Sampath, O. Kovarik, and R. Greenlaw, An Integrated Study of Thermal Spray ProcessStructure-Property Correlations: A Case Study for Plasma Sprayed Molybdenum Coatings, Mater. Sci. Eng. A Struct. Mater. Prop. Microstruct. Process., 2005, 403(1-2), p 191-204

23. A. Valarezo, W.B. Choi, W.G. Chi, A. Gouldstone, and S. Sampath, Process Control and Characterization of $\mathrm{NiCr}$ Coatings by HVOF-DJ2700 System: A Process Map Approach, J. Therm. Spray Technol., 2010, 19(5), p 852-865

24. A. Papyrin, V. Kosarev, S. Klinkov, A. Alkhimov, and V. Fomin, Cold Spray Technology, Elsevier Ltd., Oxford, 2007

25. H. Tabbara, S. Gu, D.G. McCartney, T.S. Price, and P.H. Shipway, Study on Process Optimisation of Cold Gas Spraying, J. Therm. Spray Technol., 2011, 20(3), p 608-620

26. T. Stoltenhoff, H. Kreye, and H.J. Richter, An Analysis of the Cold Spray Process and Its Coatings, J. Therm. Spray Technol., 2002, 11(4), p 542-550

27. H. Assadi, F. Gärtner, T. Stoltenhoff, and H. Kreye, Bonding Mechanism in Cold Gas Spraying, Acta Mater., 2003, 51, p 4379-4394

28. A. Yamamoto, H. Nakamura, Y. Nishiyama, and R. Kurahashi, Development of Hot-Rolled Titanium-Clad Steel Coils by Using Liquid Phase at Titanium-Steel Interface for Bonding, Nippon Steel Technical Report 62, p 34-39

29. H. Tabbara and S. Gu, Computational Simulation of Liquid Fuelled HVOF Thermal Spraying, Surf. Coat. Technol., 2009, 204(5), p 676-684

30. W.D. Swank, J.R. Fincke, D.C. Haggard, G. Irons, and R. Bullock, HVOF Particle Flow Field Characteristics, International Thermal Spray Conference, C.C. Berndt and S. Sampath, Ed., ASM International, Materials Park, OH, 1994, p 319-324

31. C.M. Hacket and G.S. Settles, Research on HVOF Gas Shrouding for Coating Oxidation Control, 8th National Thermal Spray Conference (Houston), ASM International, 1995, p 21-29

32. H. Voggenreiter, H. Huber, S. Beyer, and H.J. Spies, Influence of Particle Velocity and Molten Phase on the Chemical and Mechanical Properties of HVOF-Sprayed Structural Coatings of Alloy 316L, International Thermal Spray Conference, C.C. Berndt and S. Sampath, Ed., ASM International, Materials Park, OH, 1995, p 303-308

33. V.V. Sobolev and J.M. Guilemany, HVOF Spraying: Theory and Applications, Maney Publications, London, 1998

34. A.J. Sturgeon and D.C. Buxton, The Electrochemical Corrosion Behavior of HVOF Sprayed Coatings, International Thermal Spray Conference, C.C. Berndt, Ed., ASM International, Materials Park, OH, 2000, p 1011-1015

35. J. Kawakita, T. Fukushima, S. Kuroda, and T. Kodama, Corrosion Behaviour of HVOF Sprayed SUS316L Stainless Steel in Seawater, Corros. Sci., 2002, 44(11), p 2561-2581

36. S. Kuroda, T. Fukushima, M. Sasaki, and T. Kodama, Microstructure and Corrosion Resistance of HVOF Sprayed 316L Stainless Steel and Hastelloy C Coatings, Mater. Trans., 2002, 43(12), p 3177-3183

37. J. Kawakita, S. Kuroda, T. Fukushima, and T. Kodama, Corrosion Resistance of HVOF Sprayed HastelloyC Nickel Base Alloy in Seawater, Corros. Sci., 2003, 45(12), p 2819-2835

38. L.N. Moskowitz, Application of HVOF Thermal Spraying to Solve Corrosion Problems in the Petroleum Industry-An Industrial Note, J. Therm. Spray Technol., 1993, 2(1), p 21-30

39. V. Pershin, J. Mostaghimi, S. Chandra, and T. Coyle, A Gas Shroud Nozzle for HVOF Spray Deposition, 15th International Thermal Spray Conference (Nice), ASM International, 1998, p 1305-1308

40. J. Kawakita, S. Kuroda, T. Fukushima, and T. Kodama, Corrosion Resistance of HastelloyC Coatings Formed By An Improved HVOF Thermal Spraying Process, Mater. Trans., 2003, 44(2), p 253-258
41. J. Kawakita and S. Kuroda, Oxidation Restriction of In-Flight Particles Upon GS-HVOF Spraying by Nitrogen Addition to Combustion Gas, Mater. Trans., 2004, 45(2), p 346-349

42. H. Yamada, S. Kuroda, T. Fukushima, and H. Yumoto, Capture of HVOF Thermal Sprayed Particles by a Gel Target for Evaluation of Their In-Flight Condition, J. Jpn. Inst. Met., 2001, 65(4), p 317-322

43. J. Kawakita, S. Kuroda, and T. Kodama, Evaluation of ThroughPorosity of HVOF Sprayed Coating, Surf. Coat. Technol., 2003, 166(1), p 17-23

44. F.L. LaQue, Marine Corrosion: Causes and Prevention, John Wiley \& Sons, New York, 1975

45. J.A. Browning, Thermal Spray Method and Apparatus for Optimizing Flame Jet Temperature, U.S. Patent 5,330,798, 19 July 1994

46. J.A. Browning, Thermal Spray Method Utilizing In-Transit Powder Particle Temperatures Below Their Melting Point, U.S. Patent 5,271,965, 21 December 1993

47. D. Papamoschou and A. Roshko, The Compressible Turbulent Shear Layer: An Experimental Study, J. Fluid Mech., 1988, 197, p 453-477

48. H. Katanoda, Quasi-One-Dimensional Analysis of the Effects of Pipe Friction, Cooling and Nozzle Geometry on Gas/Particle Flows in HVOF Thermal Spray Gun, Mater. Trans., 2006, 47(11), p 2791-2797

49. G. Kleinstein, Mixing in Turbulent Axially Symmetric Free Jets, J. Spacecr., 1964, 1(4), p 403-408

50. C.K.W. Tam, J.A. Jackson, and J.M. Seiner, A Multiple-Scales Model of the Shock-Cell Structure of Imperfectly Expanded Supersonic Jets, J. Fluid Mech., 1985, 153, p 123-149

51. P.O. Witze, Centerline Velocity Decay of Compressible Free Jets, AIAA J., 1974, 12(4), p 417-418

52. B.J. McBride, S. Gordon, and M.A. Reno, Coefficients for Calculating Thermodynamic and Transport Properties of Individual Species, NASA TM-4513, 1993, p 89

53. M.J. Zucrow and J.D. Hoffman, Gas Dynamics, Vol 1, John Wiley \& Sons, New York, 1976, p 309-325

54. K. Kim, M. Watanabe, K. Mitsuishi, K. Iakoubovskii, and S. Kuroda, Impact Bonding and Rebounding Between Kinetically Sprayed Titanium Particle and Steel Substrate Revealed by HighResolution Electron Microscopy, J. Phys. D Appl. Phys., 2009, 42, p 065304

55. M. Watanabe, C. Brauns, M. Komatsu, S. Kuroda, H. Katanoda, F. Gaertner, and T. Klassen, Mechanical Properties of WarmSprayed Metallic Coatings. In Preparation, 2011

56. T. Schmidt, F. Gartner, H. Assadi, and H. Kreye, Development of a Generalized Parameter Window for Cold Spray Deposition, Acta Mater., 2006, 54, p 729-742

57. K. Binder, J. Gottschalk, M. Kollenda, F. Gärtner, and T. Klassen, Influence of Impact Angle and Gas Temperature on Mechanical Properties of Titanium Cold Spray Deposits, J. Therm. Spray Technol., 2010, 20(1-2), p 232-242

58. M. Watanabe, C. Brauns, M. Komatsu, and S. Kuroda, Japan Thermal Spray Society Fall Meeting, 2010, p 1-2

59. F. Gärtner, T. Stoltenhoff, J. Voyer, H. Kreye, S. Riekehr, and M. Koçak, Mechanical Properties of Cold-Sprayed and Thermally Sprayed Copper Coatings, Surf. Coat. Technol., 2006, 200(24), p 6770-6782

60. P. Chivavibul, M. Watanabe, S. Kuroda, and K. Shinoda, Effects of Carbide Size and Co Content on the Microstructure and Mechanical Properties of HVOF-Sprayed WC-Co Coatings, Surf. Coat. Technol., 2007, 202(3), p 509-521

61. M. Watanabe, A. Owada, S. Kuroda, and Y. Gotoh, Effect of WC Size on Interface Fracture Toughness of WC-CoHVOF Sprayed Coatings, Surf. Coat. Technol., 2006, 201(3-4), p 619-627

62. S. Kuroda and M. Watanabe, Structure and Properties of Thermal Sprayed Cermet (WC-Co) Coatings, J. High Temp. Soc., 2010, 36, p 254-263 (in Japanese)

63. M. Watanabe, G.S. Raman, M. Komatsu, S. Kuroda, K. Sato, and J. Kitamura, Japan Thermal Spray Society Spring Meeting (Osaka), 2010, p 39-40

64. S. Kuroda, G.S. Raman, M. Watanabe, M. Komatsu, K. Sato, and J. Kitamura, International Thermal Spray Conference (Singapore), 2010 